STRUCTURAT ANALYSIS OF THE

CDE TRANSPORTER CART

Mark Leininger

November 17, 1982

Abstract

The transporter cart serves as a dolly to move the large toroids (539 tons) and the Roman arches (600 tons) which are part of the central detector. ANSYS has been used to compute deflections and stresses in this cart.

\title{
Introduction
}

Fig. I shows the computer model of the transporter cart used for the analysis. Only half the cart is modeled in the x direction, with symmetry constraints along the edge $\mathrm{x}=72.0$ in. preventing a change in slope there. The cart is made by welding together the flanges of $W 33 \times 130.0$ beams along the $\mathrm{z}$ axis which leads to a rather weak structure along the $\mathrm{x}$ axis. The webs of the W33 $\times 130.0$ beams are shown in Fig. 2. To strengthen the cart along the $\mathrm{x}$ axis, steel ribs are welded in the web of the wide flange beams (Fig. 3 and 4) resulting in a "table" with good strength in both the $\mathrm{x}$ and $\mathrm{z}$ directions. The cart is campleted by welding steel plates around the edges (Fig. 5 and 6) and on top and bottom (Fig. 7 and 8). It is the plate on the bottom (Fig. 7) where the cart will be supported. Support is provided either by large screw jacks when the cart is in a stationary position or by 
Hilman rollers when the cart is being moved. Fig. 9 shows the reinforcing plates which the screw jacks and rollers actually contact. Figs. 10 and 11 show the location of the screw jack and roller locations used for the analysis. Those familiar with the cart will notice that these locations are not exactly the same as planned for the cart. This is due to the nodal locations required to allow the problem to be solved with the incore storage available on the Cyber. Note that the locations chosen for the model will in all cases cause the deflections and stresses to be slightly higher than in the actual cart.

\section{Verification Problem}

Because of the large physical size of this cart, the number of nodes used to model it had to be held to a minimum to allow a solution. As a consequence, the elements used to model the wide flange beams had to be rather large, approximately 6 in. by 6 in. sqare in the flanges and 6 in. $x 11$ in. high in the web. To establish the accuracy of using this size element, a simple analysis of the same W33 $\times 130.0$ beam used in the cart is performed using the same size elements. Fig. 12 shows an isometric view of the beam. Figs. 13 and 14 show views of the web and top flange of the beam. Note that only half the beam is actually modeled. Also note the beam is slightly modified due to the fact that each flange is $1 / 2 \mathrm{in}$. wider due to welding the flanges together. The beam is simply supported with a 5000 lb. load applied at the midpoint. The solution to this problem may be computed analytically using Roark and Young, "Formulas for Stress and Strain," page 97, case le: 


$$
\mathrm{Y}=\frac{\mathrm{W} \ell^{3}}{48 \mathrm{EI}} \text { where } \quad \begin{aligned}
& \mathrm{W}=5000 \mathrm{Ib} . \\
& \ell=324 \mathrm{in.} \\
& \mathrm{E}=30 \times 10^{6} \mathrm{psi} \\
& \mathrm{I}=6955.5 \mathrm{in} .^{4} \\
& \mathrm{C}=16.12 \mathrm{in} .
\end{aligned}
$$

$$
\begin{aligned}
& \mathrm{y}=0.01698 \mathrm{in} . \\
& \mathrm{M}_{\max }=\frac{\mathrm{Wl}}{4}=405,000 \text { in. } 1 \mathrm{~b} . \\
& \sigma=\frac{\mathrm{MC}}{\mathrm{I}}=\mp 940 \mathrm{psi} \text { (compression on top, tension on bottom) }
\end{aligned}
$$

Because of the depth of this beam, shear deflections (which are included in the ANSYS solution) may be significant. These shear deflections are computed using Roark, page 185:

$$
\mathrm{Y}=\text { shear deflection }=\frac{1}{4} \mathrm{~F} \frac{\mathrm{Wl}}{\mathrm{AG}}=0.002 \mathrm{in} .
$$

where:

$$
\begin{aligned}
& \mathrm{A}=38.3 \mathrm{in} .^{2} \\
& \mathrm{G}=11 \times 10^{6} \mathrm{psi} \\
& \mathrm{F}=\left[1+\frac{3\left(\mathrm{D}_{2}^{2}-\mathrm{D}_{1}^{2}\right) \mathrm{D}_{1}}{2 \mathrm{D}_{2}^{3}}\left(\frac{\mathrm{t}_{2}}{\mathrm{t}_{1}}-1\right)\right] \frac{4 \mathrm{D}_{2}^{2}}{10 \mathrm{r}^{2}}=2.40 \\
& \mathrm{D}_{1}=\text { distance from neutral axis to nearest surface of flange }=15.69 \mathrm{in} . \\
& \mathrm{D}_{2}=\text { distance from neutral axis to extreme fiber }=16.545 \mathrm{in} . \\
& t_{1}=\text { thickness of web }=.580 \\
& t_{2}=\text { width of flange }=12.01 \\
& r=\text { radius of gyration }=13.2
\end{aligned}
$$


Adding (1) and (4), one gets an analytic solution for the total deflection of $0.0190 \mathrm{in}$. The ANSYS solution is 0.0194 . The analytic solution for stresses at the center in the extreme fibers is 940 psi, the ANSYS solution is $1028 \mathrm{psi}$ tension in the bottom flange and 1168 psi compression in the top flange. The ANSYS stress values are, therefore, high by about 15 percent while the defelctions are nearly exact.

Figs. 15 through 24 show the distorted shape of the beam under load and the various stress contours in the beam due to the load.

\section{Analysis of the Cart}

Because only half of the cart is being modeled, the only place the loads can be applied is along the symmetry cut (the plane $\mathrm{x}=72.0 \mathrm{in.}$ ). The only loading which need be considered is due to the Roman arch assembly. The large toroid is never manipulated in such a way that its load falls anywhere except along the wide flange beams which have support under them. The Roman arch will apply loading on the "middle" of the cart as shown in Fig. 25. A very crude way to estimate the deflections and stresses due to the load of the Roman arch is to assume that each 75 ton footprint is carried at the midpoint of two w33 $\times 130.0$ beams made up of the crossribs shown in Fig. 3. This leads to the following result:

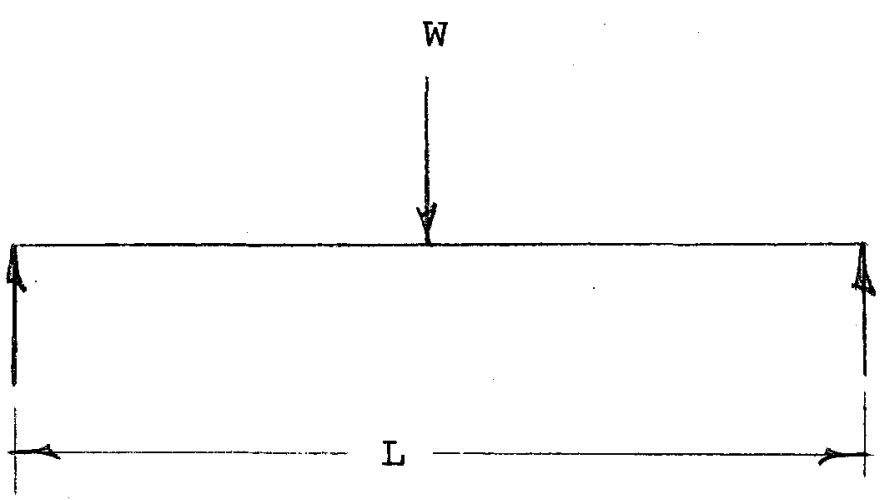


where:

$$
\begin{aligned}
& W=75 \text { ton }=150,000 \mathrm{lb} \text {. } \\
& \mathrm{I}=139 \text { in. } \\
& \mathrm{E}=30 \mathrm{E} 6 \mathrm{psi} \\
& I=13,420 \text { in. } 4 \\
& \mathrm{~s}=812 \text { in. } 3 \\
& M=\frac{W}{2} \cdot \frac{L}{2}=\frac{W L}{4}=\frac{(150,000)(139)}{4}=5.21 E 6 \text { in. 1b. } \\
& \sigma=\frac{M}{S}=\frac{5.21 \mathrm{E} 6 \text { in. } \mathrm{lb}_{\mathrm{b}}}{812 \mathrm{in.} .^{3}}=6420 \text { psi } \\
& y=\frac{\mathrm{W}^{3}}{48 \mathrm{EI}}=\frac{(1.5 \mathrm{E} 5)(139)^{3}}{(48)(30 \mathrm{E} 6)(13,420)}=0.021 \mathrm{in}
\end{aligned}
$$

One, therefore, expects stresses of the order 6,400 psi and deflections at the load of about $0.021 \mathrm{in}$. This number does not include the weight of the beams. The stresses and deflections due to the weight of the beams will be:

$$
\begin{aligned}
& M=\frac{q L^{2}}{8}=\frac{(22.1)(139)^{2}}{8}=5.337 \mathrm{E} 4 \mathrm{in} . \mathrm{lb} . \\
& \sigma=\frac{M}{\mathrm{~S}}=\frac{5.337 \mathrm{E} 4}{812}=66 \mathrm{psi} \\
& y=\frac{5 \mathrm{gL}}{384 \mathrm{EI}}=\frac{(5)(22.1)(139)^{4}}{(384)(30 \mathrm{E} 6)(13,420)}=.0003 \mathrm{in} .
\end{aligned}
$$

The weight of the structure itself is, therefore, not significant. 
The ANSYS solution results in a maximum deflection of 0.029 in. for the case of screw jack support and $0.024 \mathrm{in}$. for the case of roller support. The distorted geometiy for these two cases is shown in Fig. 26-31.

The maximum Von Mises stresses for the two cases turns out to be 3940 psi for the case of the screw support and 3800 psi for the case of roller supports. Both maximms occur at node 3514 which is located on the top plate directly under the Roman arch load closest to the center of the table.

The actual construction of the table requires plug welding the top plate on the flanges of the beams. There is an interest in knowing the shear on these welds so that the number of welds required can be determined. There is no direct way to extract this information from the solution, but an approximation can be made. Consider a rectangular beam in bending. The shear varies parabolically from a maximm at the center to 0 at the free surfaces:

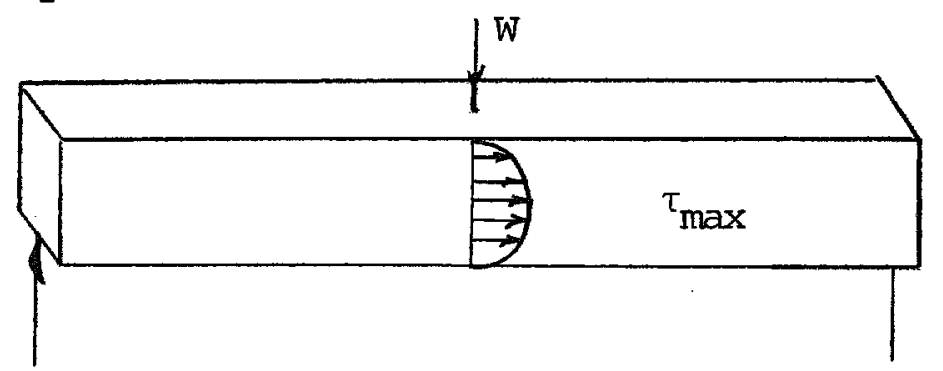

However, for a wide flange beam, the shear stresses through the web are nearly constant, provided the thickness of the web is small compared to the width of the flange. This being the case, the approximation to be made is to take the shear stress in both directions acting in the webs of the beams ( $\tau_{y x}$ and $\tau_{y z}$ ) divide by the total shear area of the webs, and use the resulting shear force to size the welds. From ANSYS, the max shear is $\tau_{y x}=1700$ (assume this acts in both directions). The total web area for beams running in the $\mathrm{x}$ direction is $6(0.580)(332)=1155$ in. $^{2}$ and in the $z$ direction is $10(.750)(144)=1080$ in. $^{2}$ 
The total shear force in each direction is then:

$$
\begin{aligned}
& \mathrm{Nx}=\left(\tau_{\mathrm{yx}}\right)(1155)=1.96 \mathrm{E} 6 \mathrm{lb} . \\
& \mathrm{Nz}=\left(\tau_{\mathrm{yx}}\right)(1080)=1.84 \mathrm{E} 6 \mathrm{lb} .
\end{aligned}
$$

There will be 52 plug welds, each 2 in. diameter for a total shear area of $163 \mathrm{in.}^{2}$. The maximum shear force will be:

$$
\mathrm{N}=\left(\mathrm{Nx}{ }^{2}+\mathrm{Ny}^{2}\right)^{1 / 2}=\left((1.96 \mathrm{E} 6)^{2}+(1.84 \mathrm{E} 6)^{2^{1 / 2}}=2.7 \mathrm{E} 6 \mathrm{lb}\right.
$$

The resulting shear stress in the welds will be:

$$
\tau_{\text {weld }}=\frac{2.7 \mathrm{E} 6 \mathrm{lb} .}{163 \mathrm{in.}^{2}}=16,000 \mathrm{psi}
$$

For this very worst case analysis, the indication is that the number of welds is sufficient.

\section{Conclusions}

The deflections are much less than $L / 360$, and the stresses are not even moderate for structural steel. There appears to be no problems at all. 
$T M-1148$

$-8-$

Fig. 1

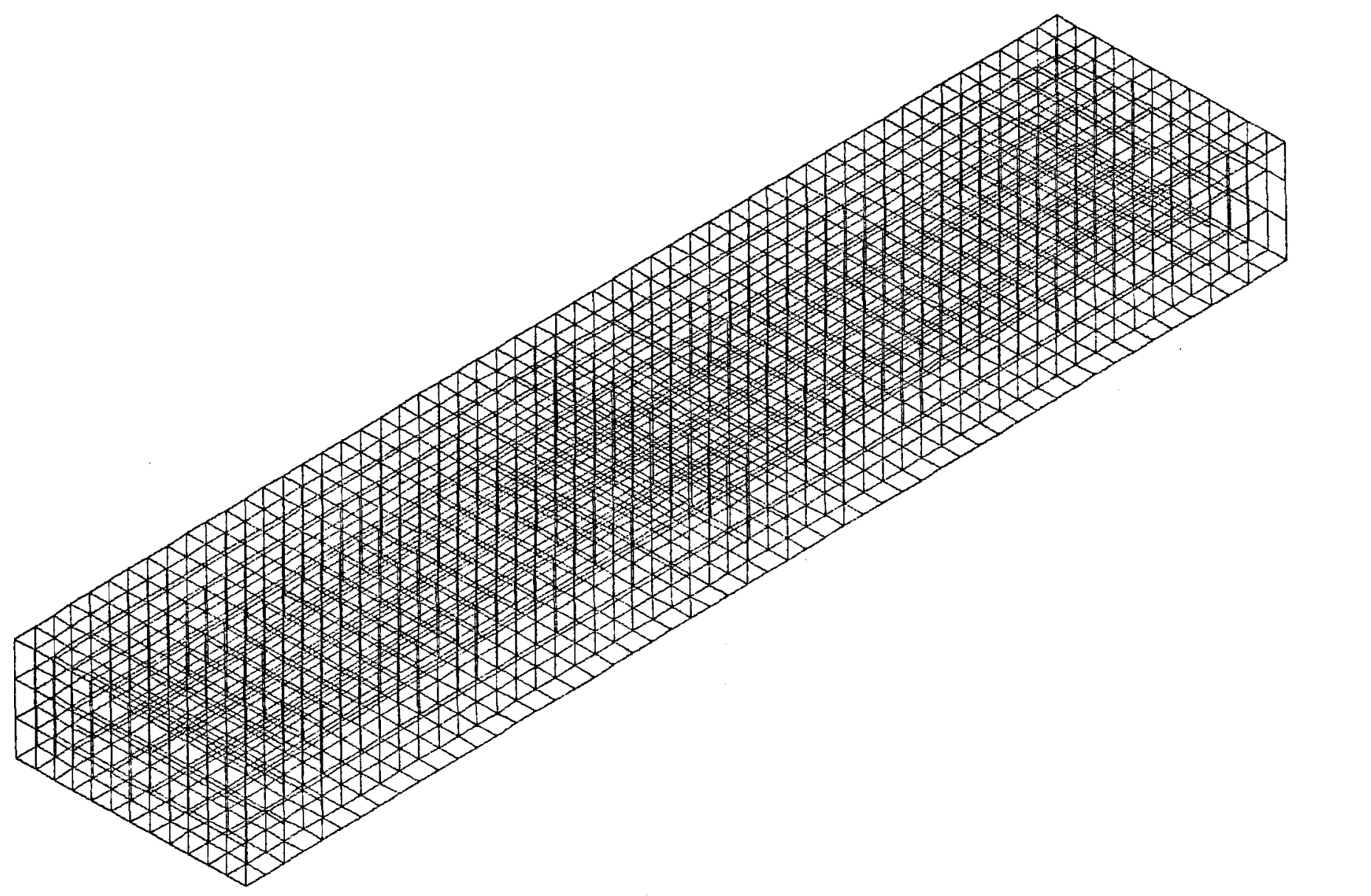


Fig. 2

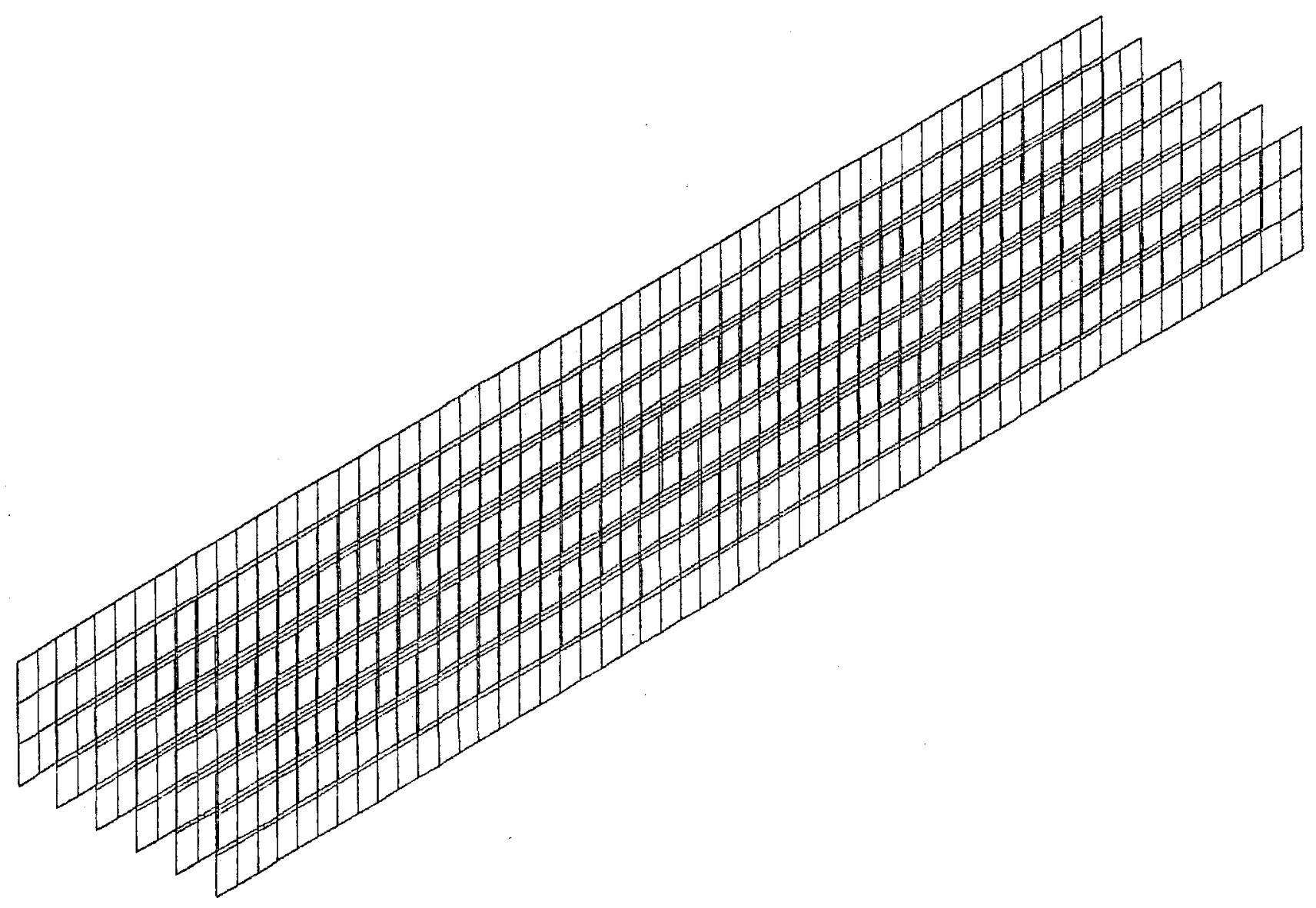


Fig. 3
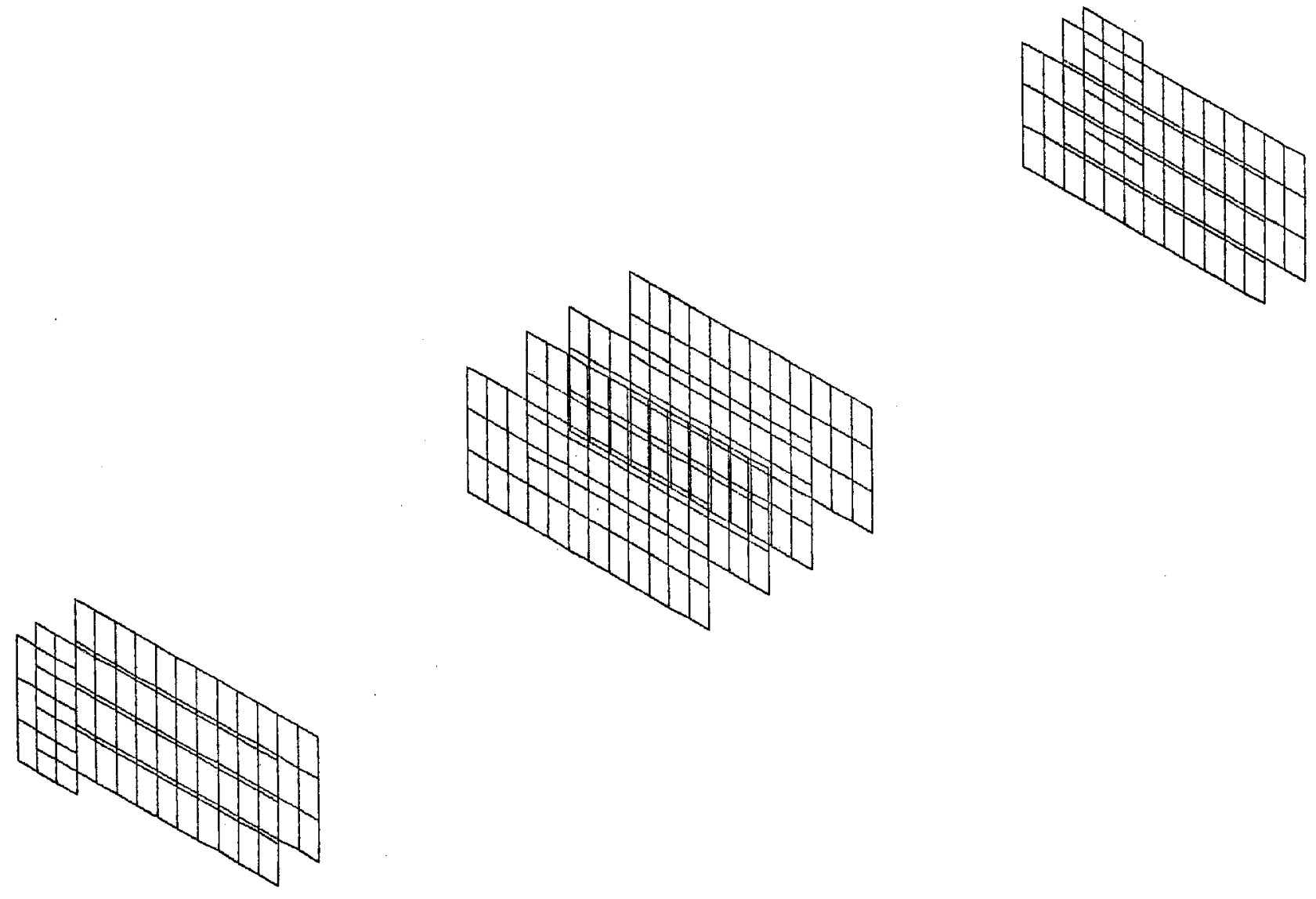
$-11-$

Fig. 4

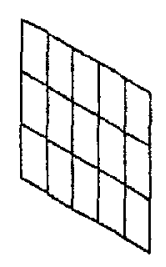


$T M-1148$

$-12-$

Fig. 5
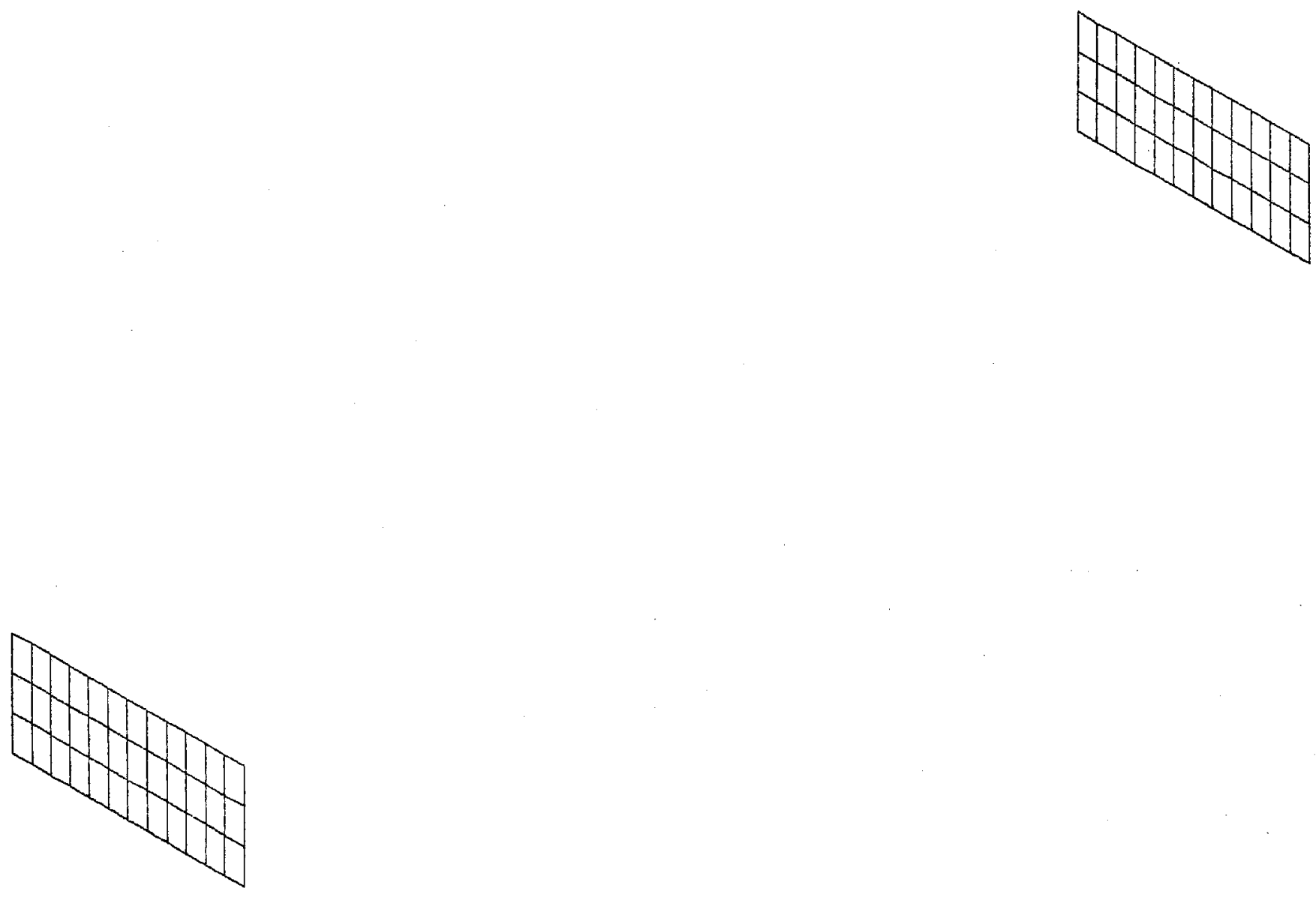

TRANSFER TABLE. MODEL CHECK. 
$T M-1148$

$-13-$

Fig. 6

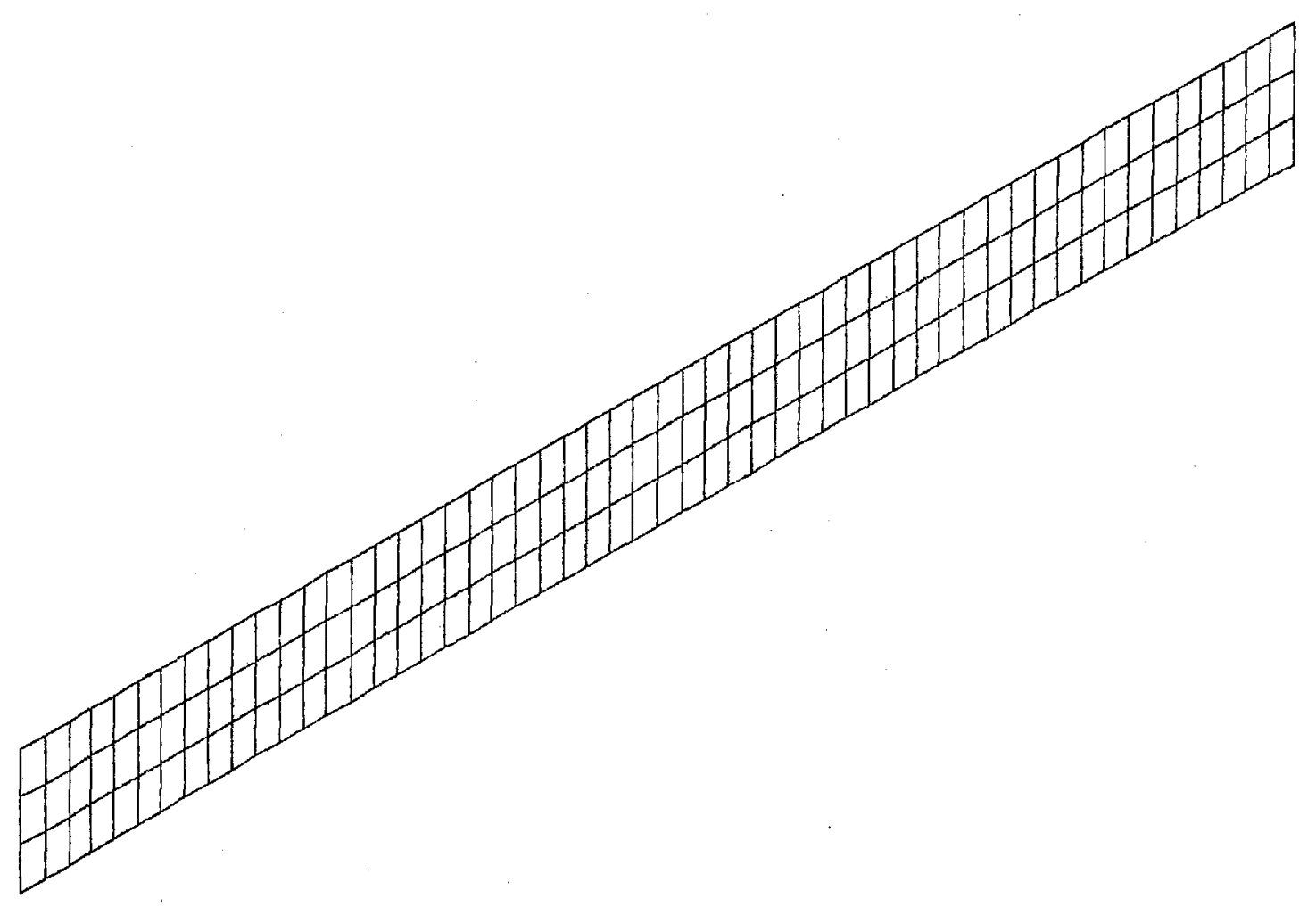


$-14-$

Fig. 7
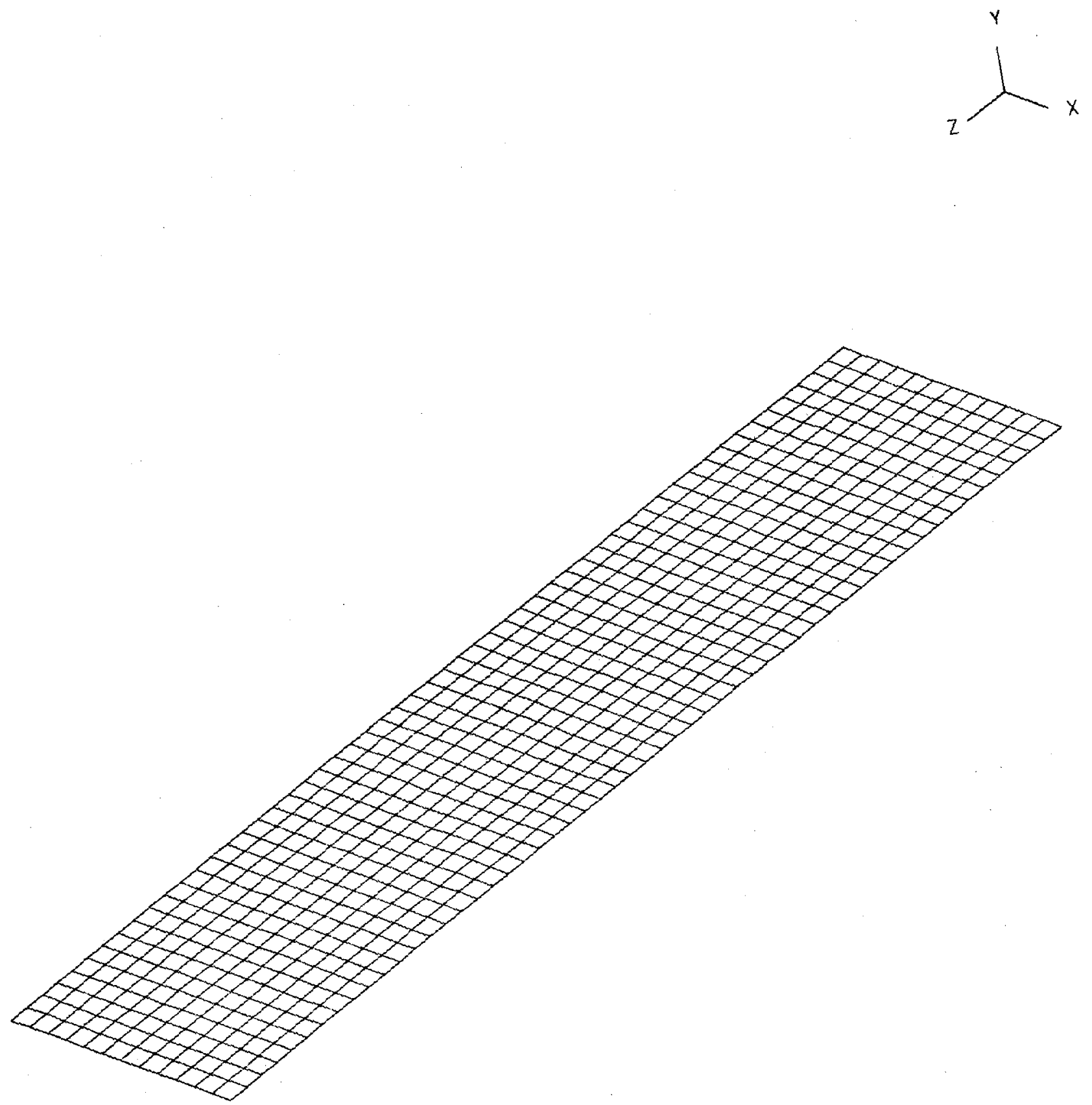

GEDMETF

RUECK. 


\section{$-15-$}

Fig. 8

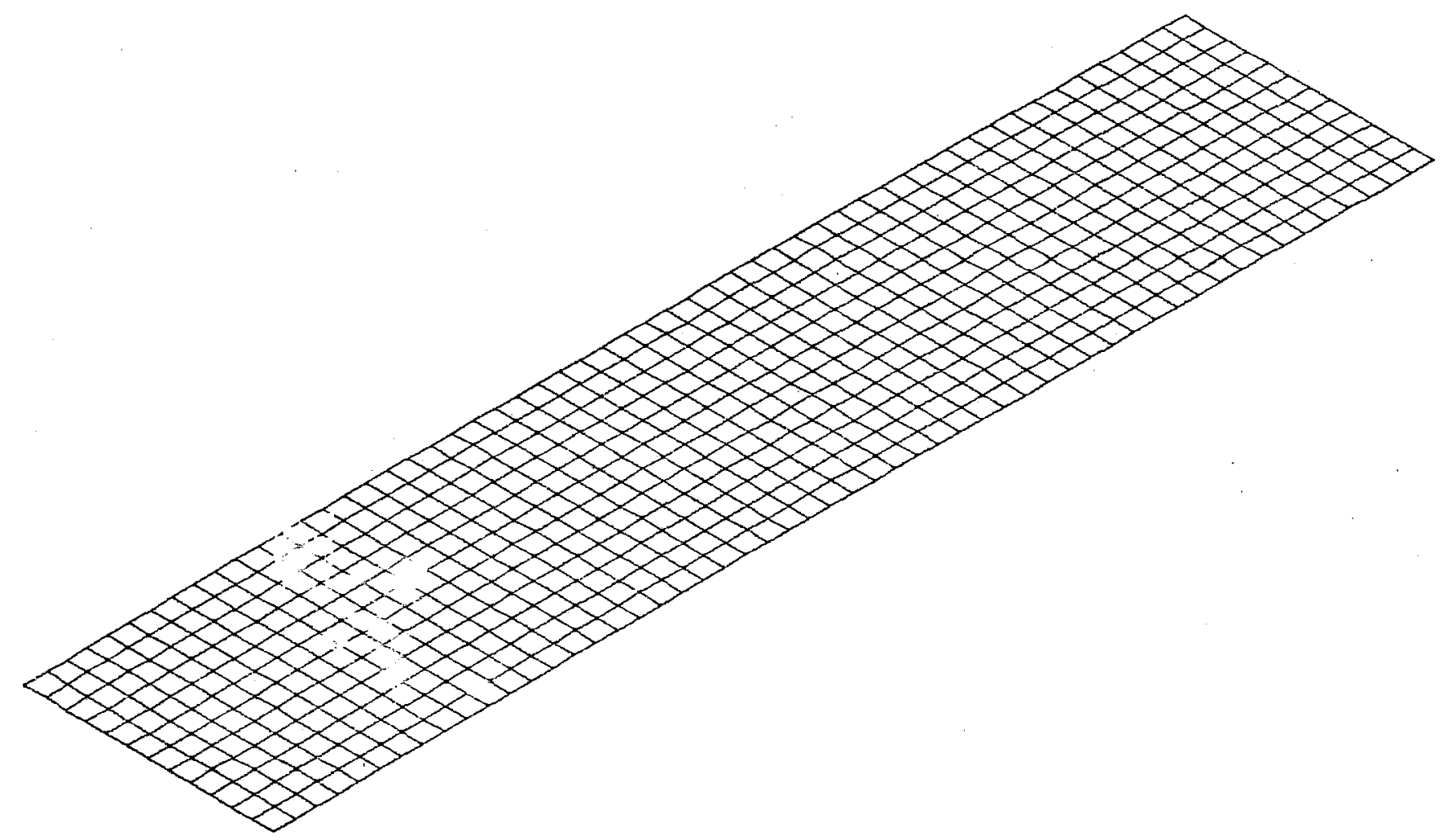

TAANSFER TABLE. MODEL CHECK 
Fig. 9
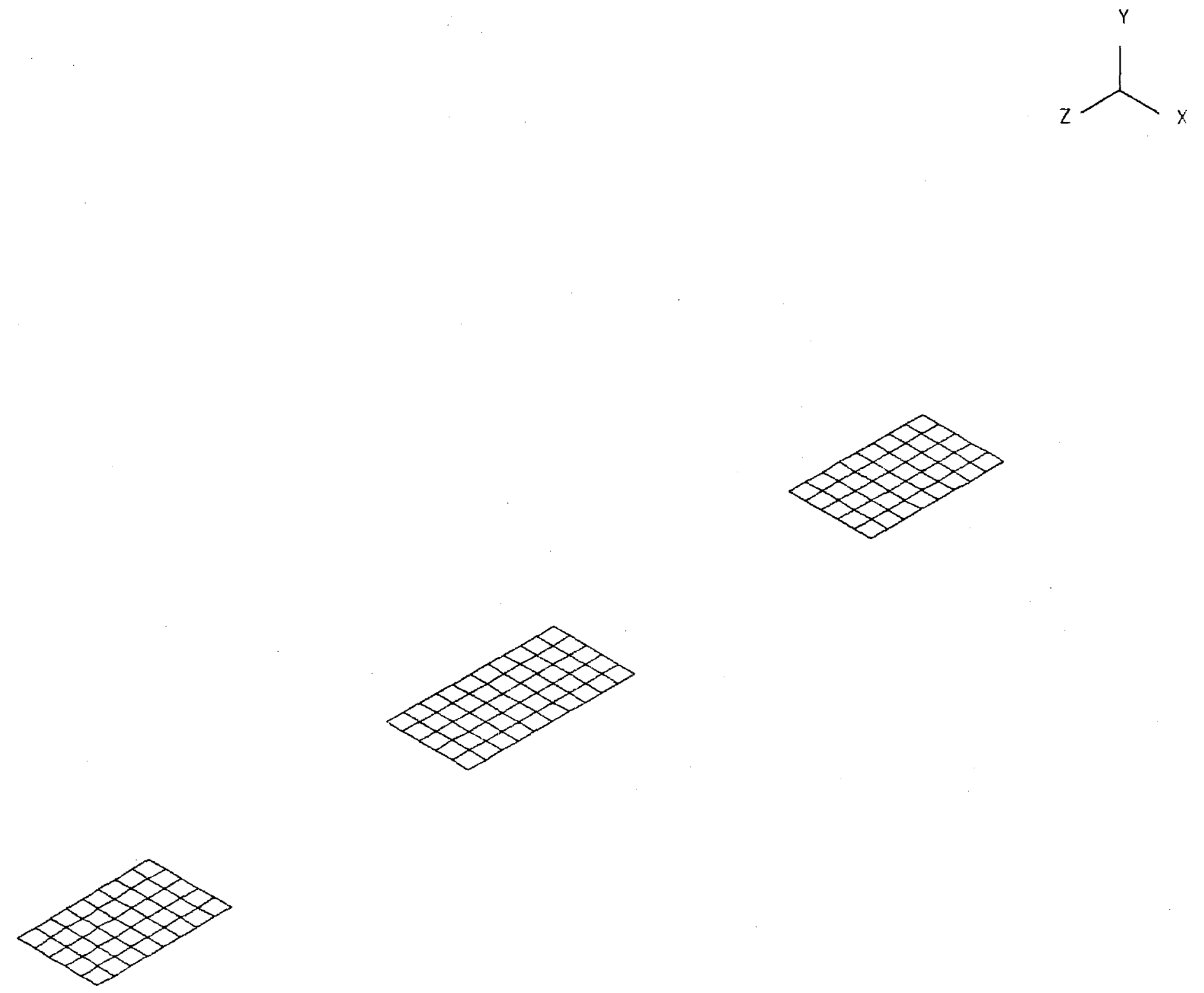
$T M-1148$

$-17-$

Fig. 10

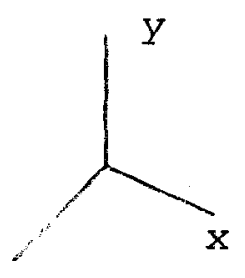

Z

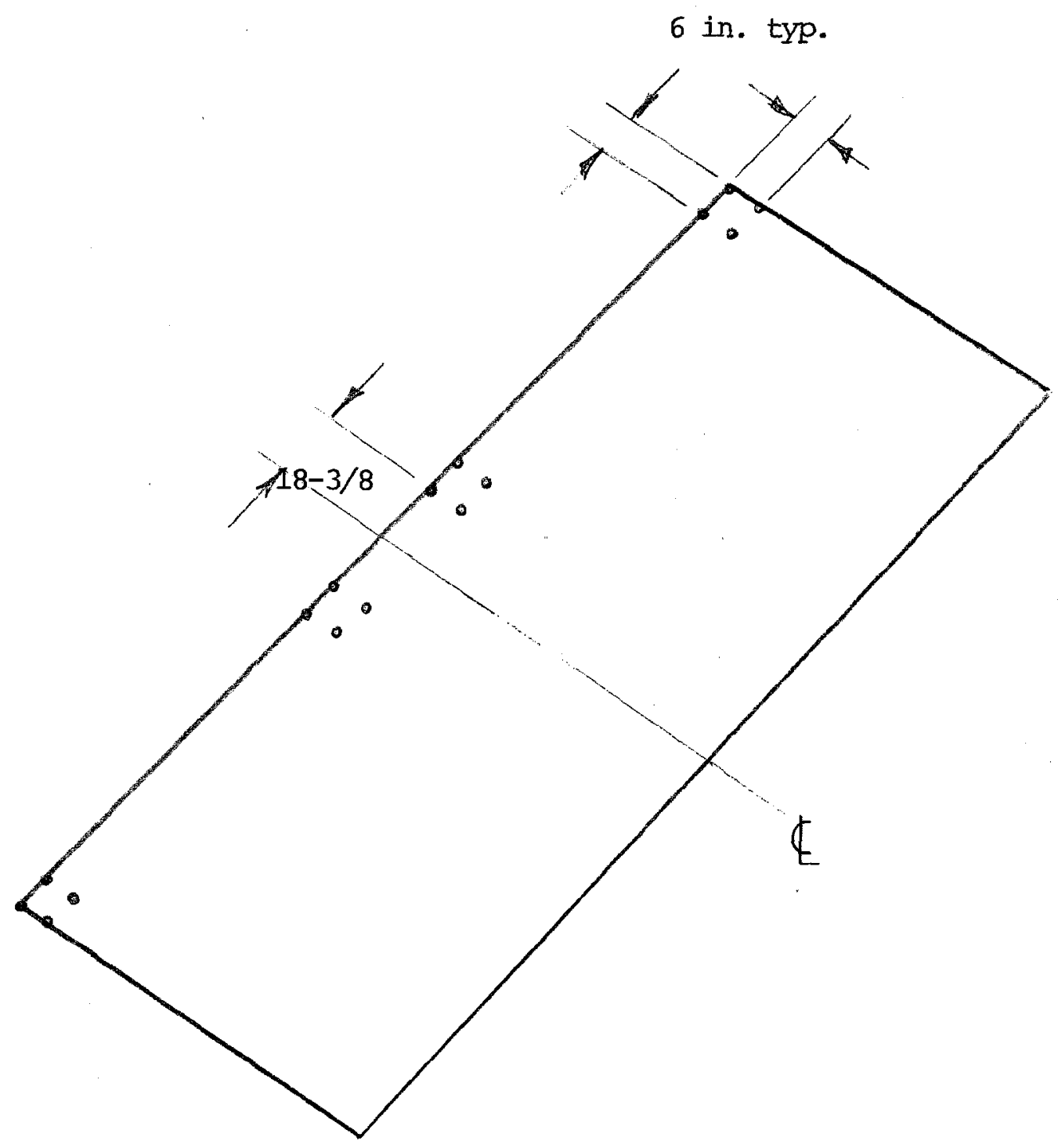

Location of screw jack supports. Each support modeled as 4 nodes spaced 6 in. $x 6$ in. having y degree of freedom constrained. 
Fig. 11

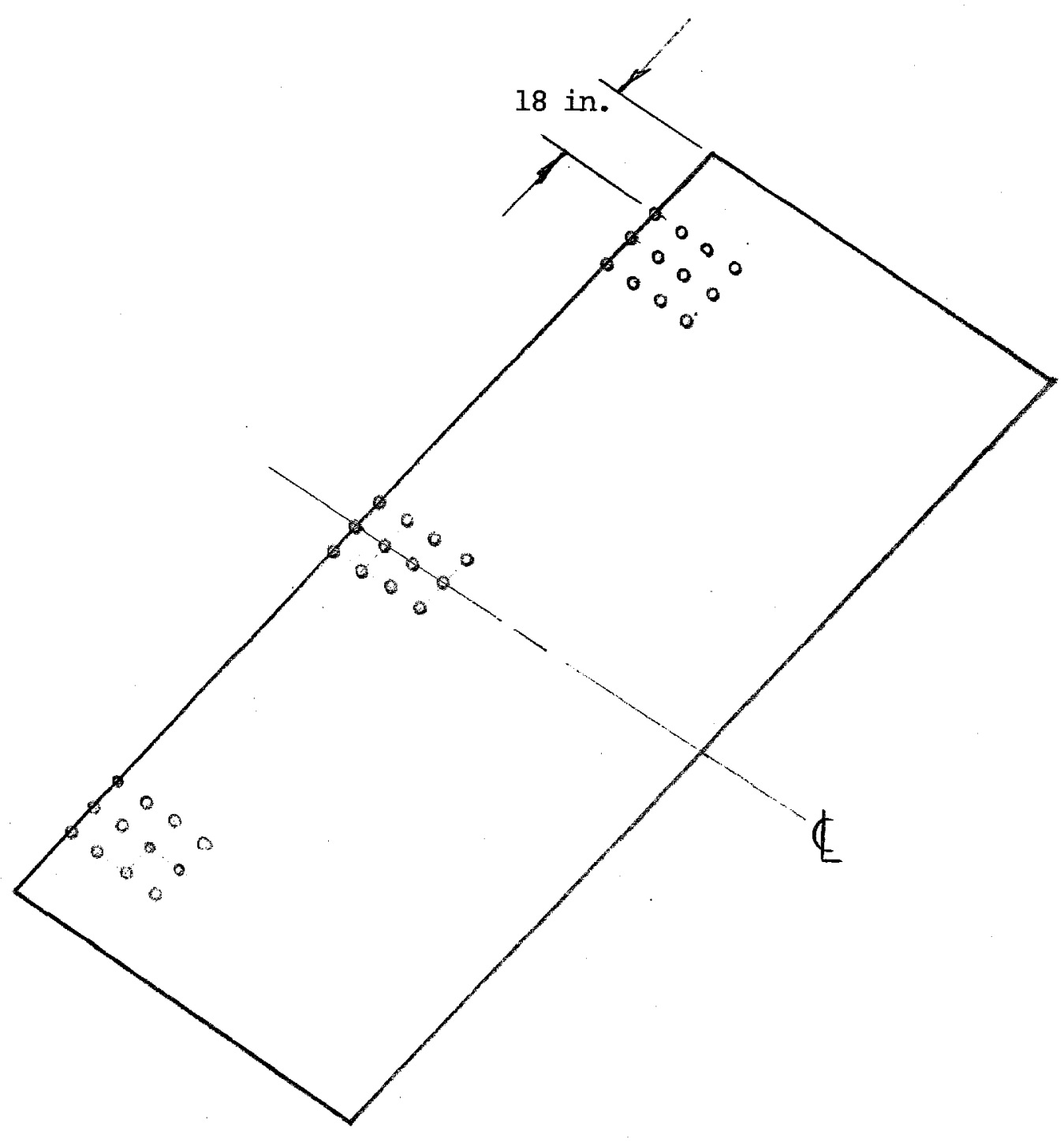

Location of Hilman roller supports. Each roller modeled as 12 nodes located as shown having the $y$ degree of freedom constrained. All nodes are 6 in. from their nearest neighbor. 
TM-1148

$-19-$

Fig. 12
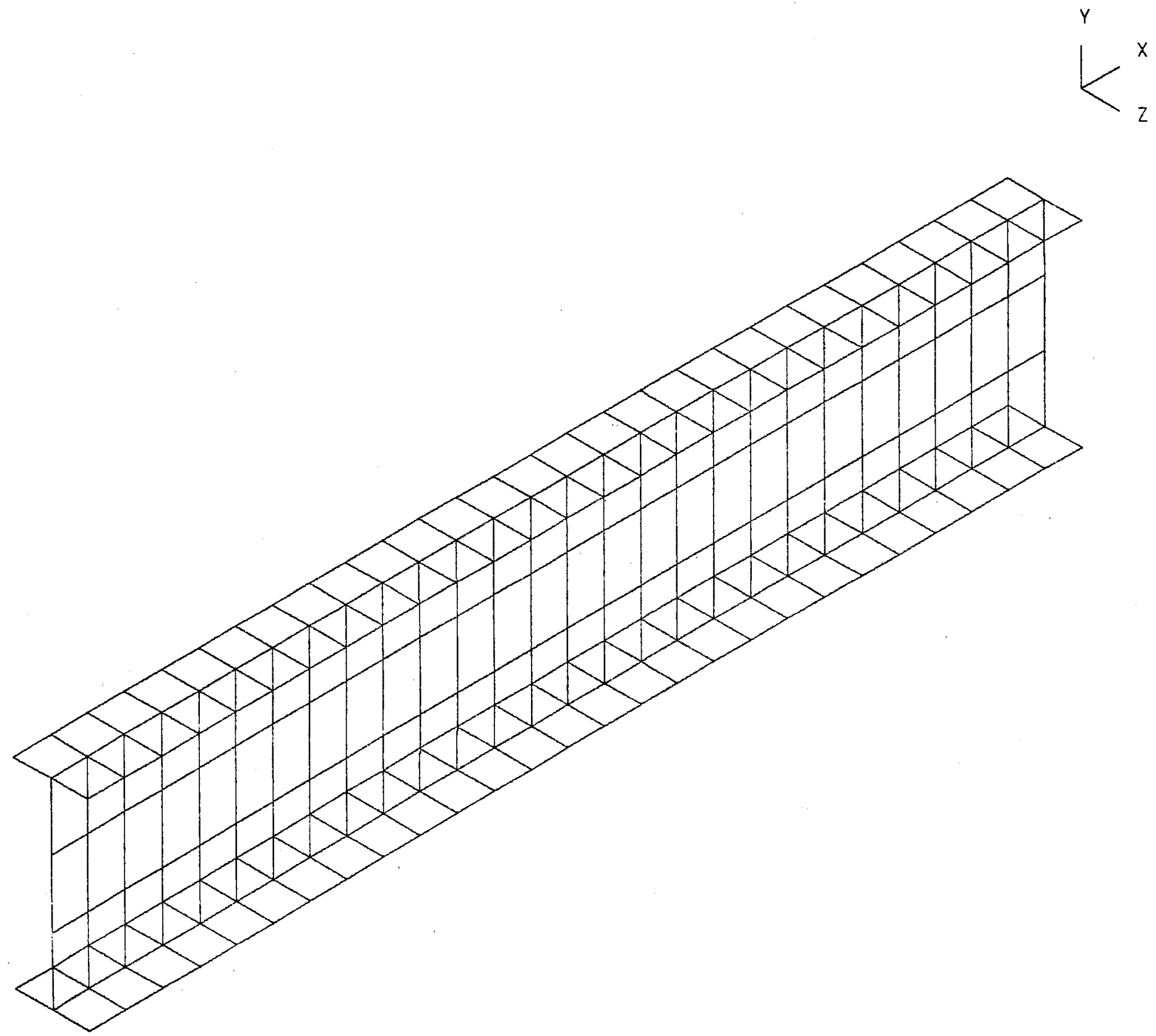
Fig. 13

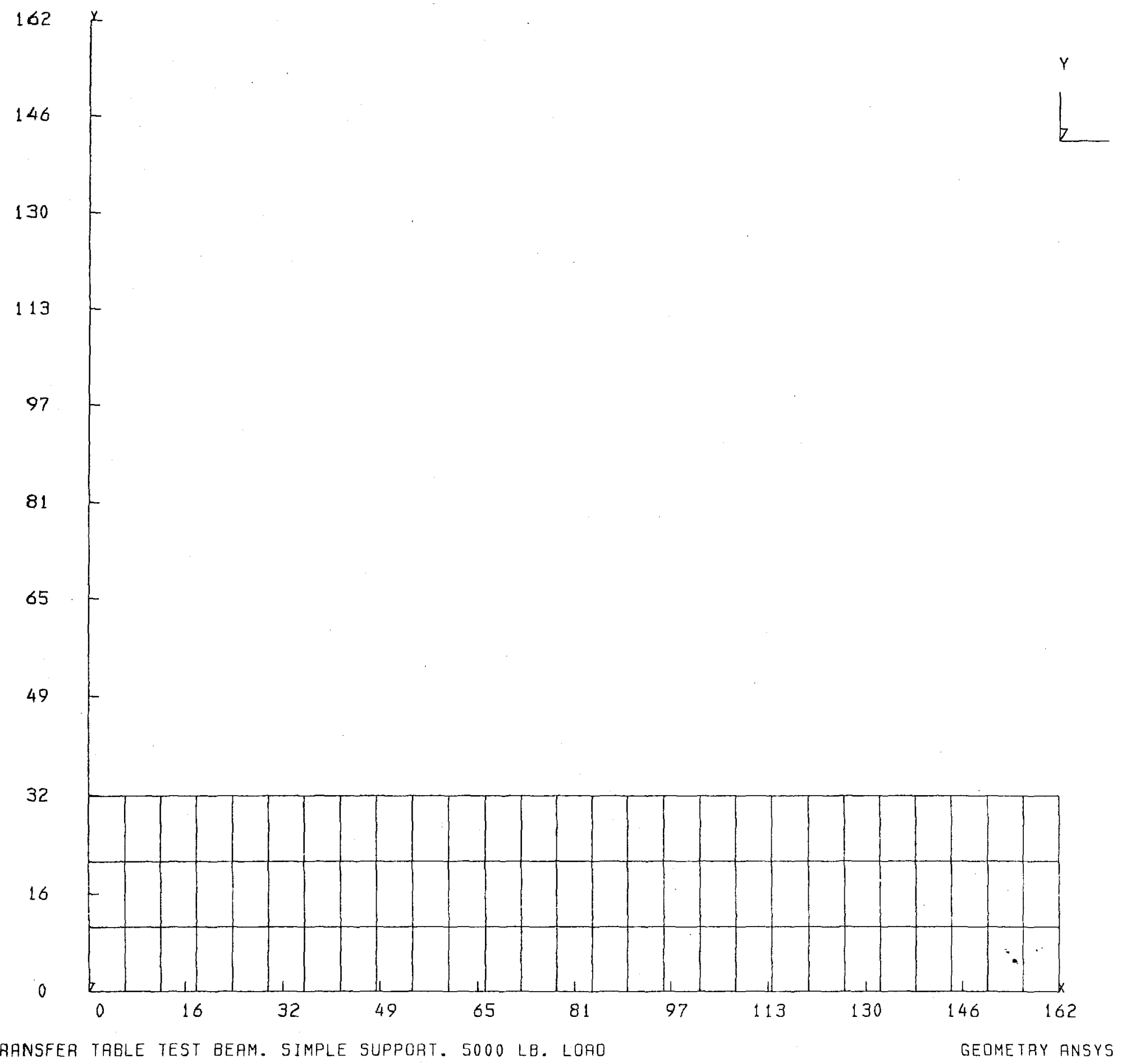


$-21-$

Fig. 14

\begin{tabular}{|l|l|l|l|l|l|l|l|l|l|l|l|l|l|l|l|l|l|l|l|l|l|l|l|l|l|l|}
\hline & & & & & & & & & & & & & & & & & & & & & & & & & \\
\hline
\end{tabular}


Fig. 15

STEP $=1$ ITER $=1$ TIME $=0$

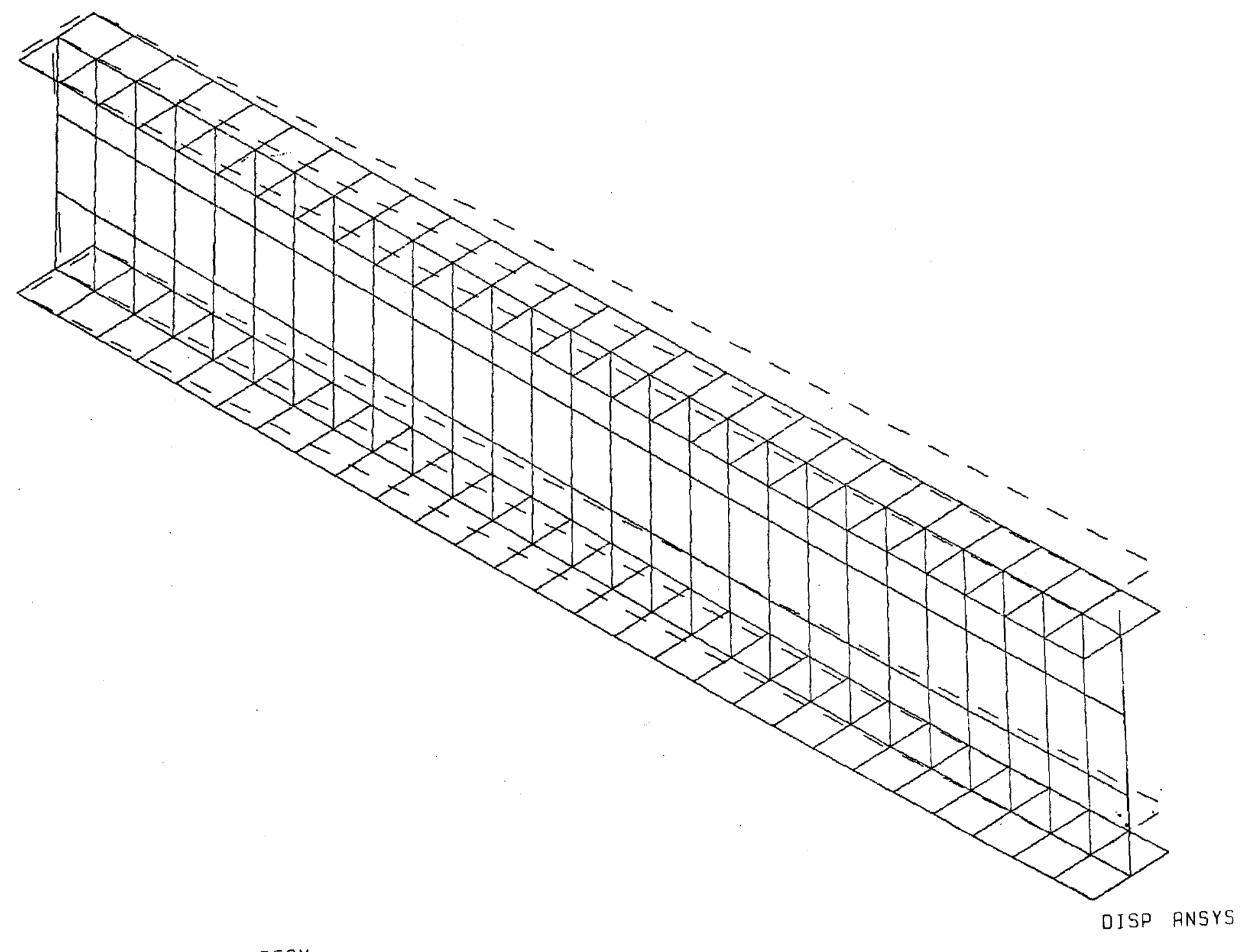


Fig. 16

STEP $=1$ ITEA $=1$ TIME $=1$ O
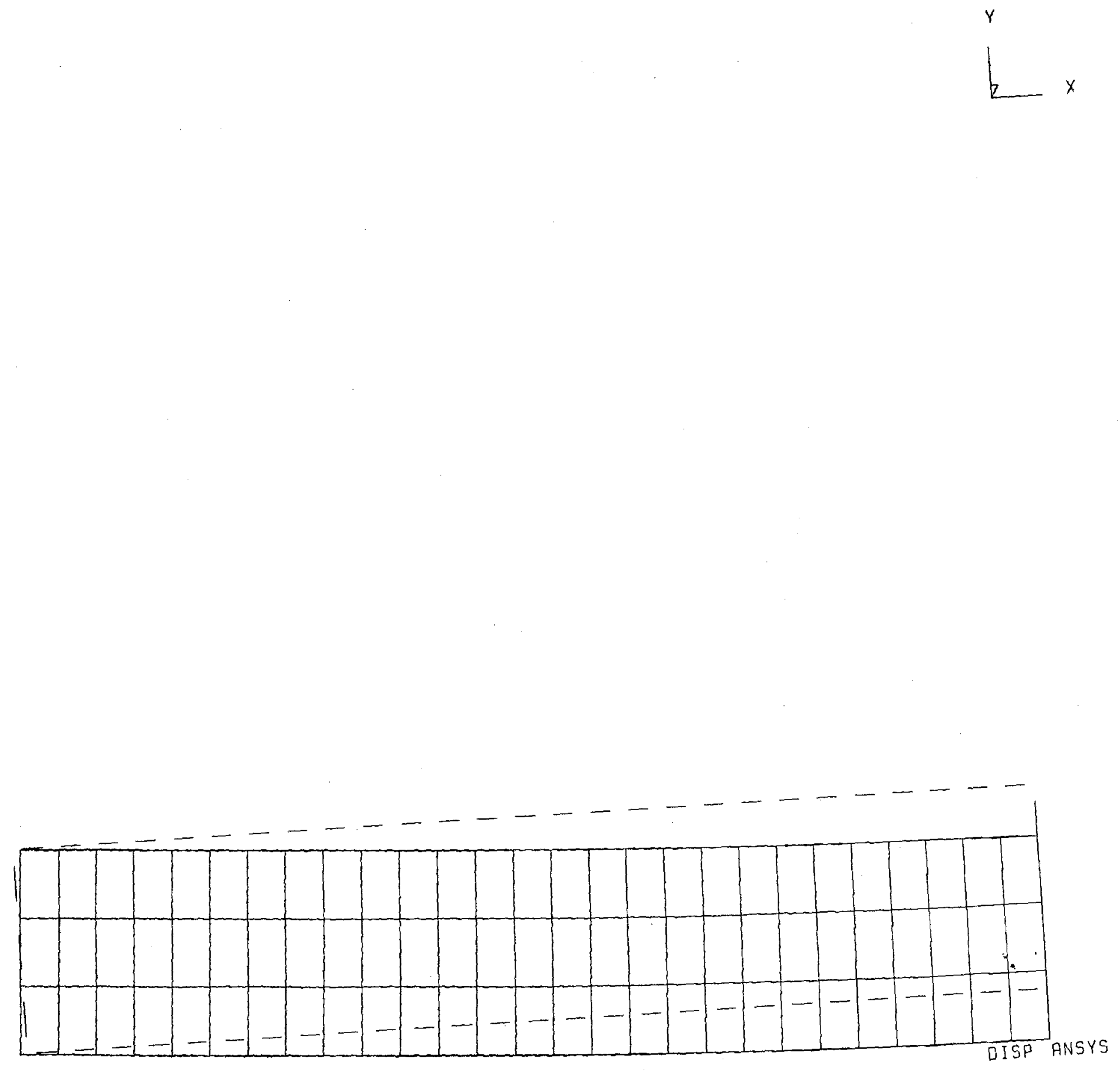
Fig. 17

STEP $=1$ ITER $=1$ TIME $=0$
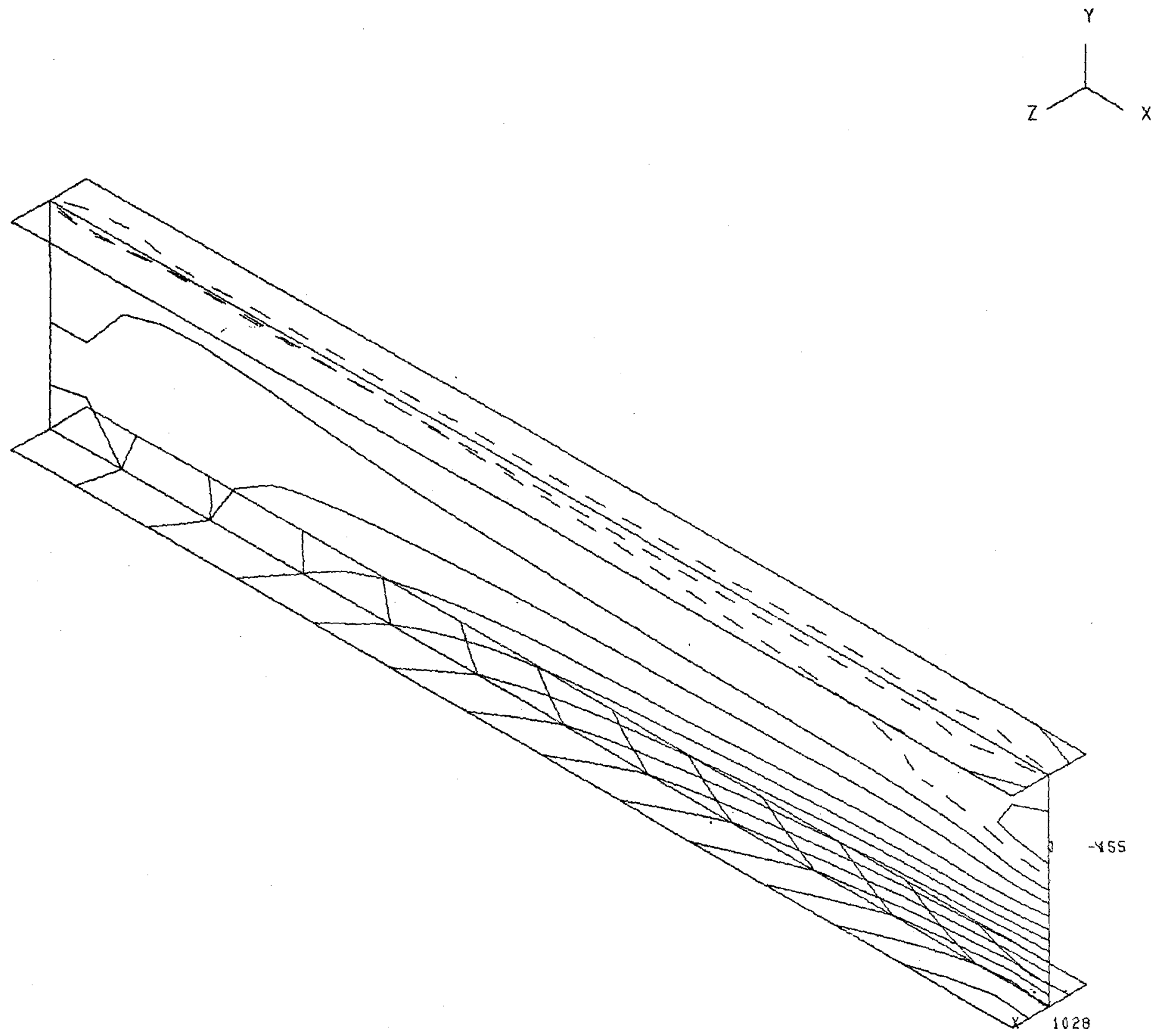
Fig. 18

STEP $=1$ ITER $=1$ TIME $=0$

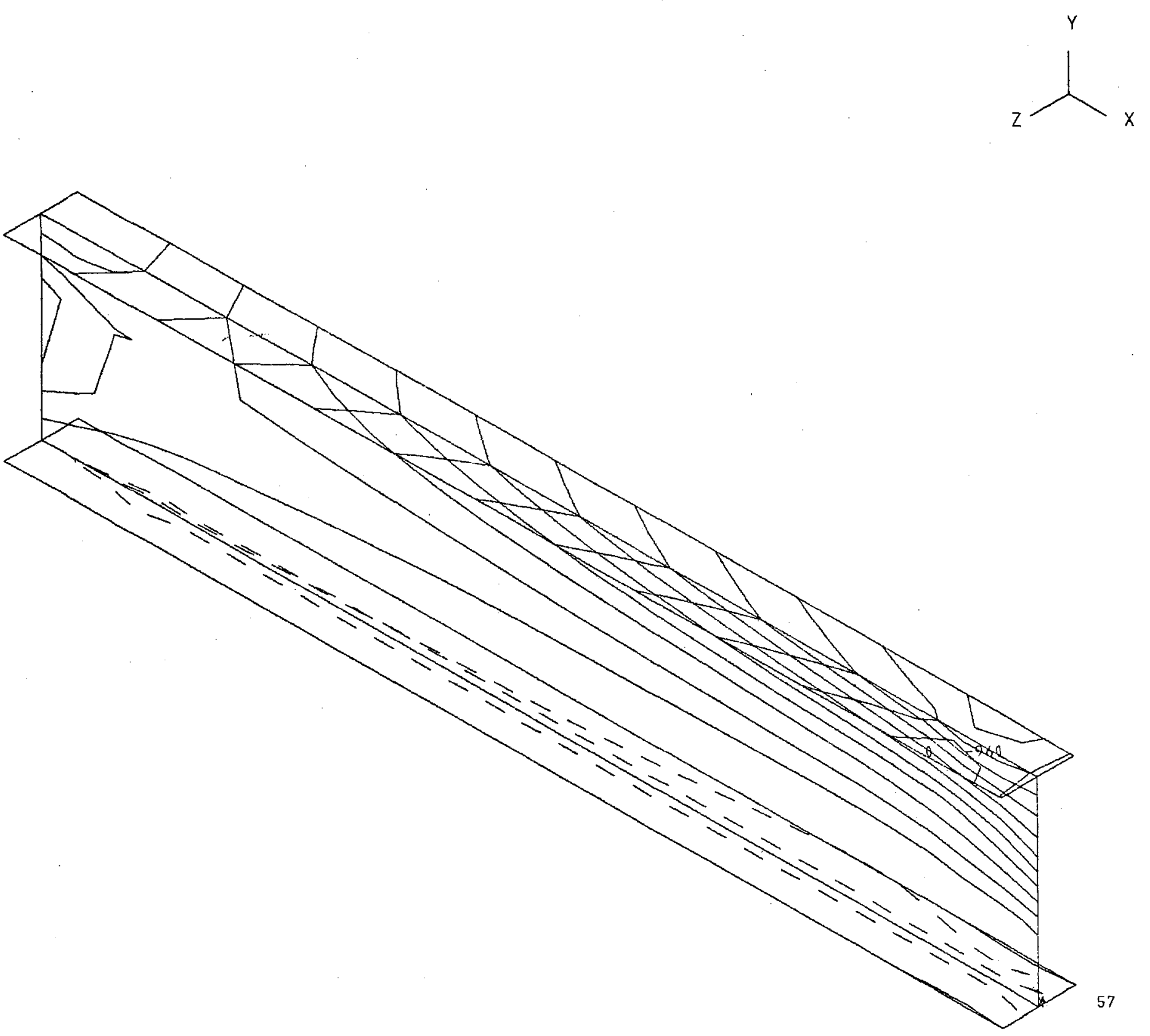


Fig. 19

STEP $=1$ ITER $=1$ TIME $=0$

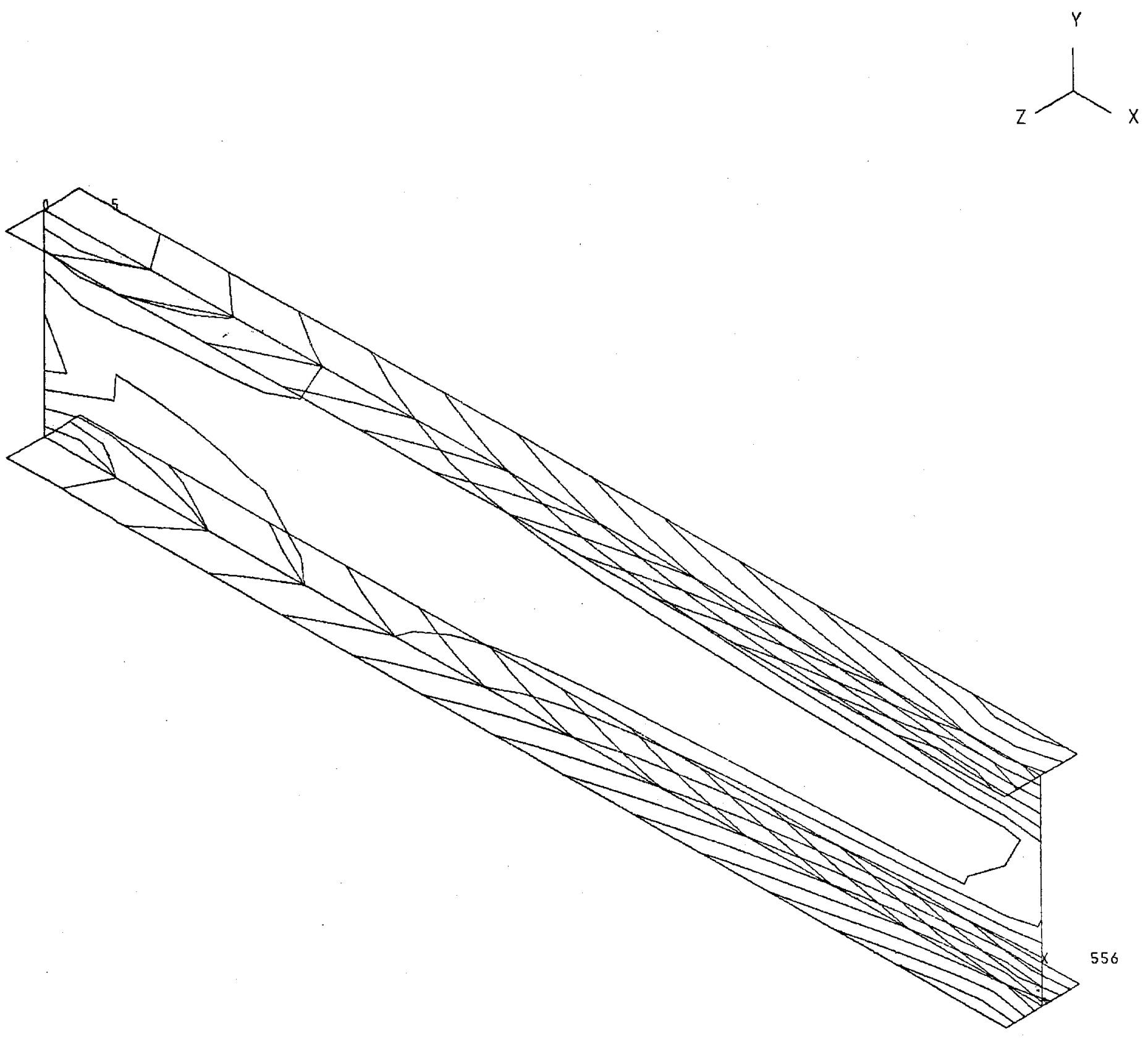


Fig. 20

STEP $=1$ ITEA $=$ I TLME $=0$

80.00
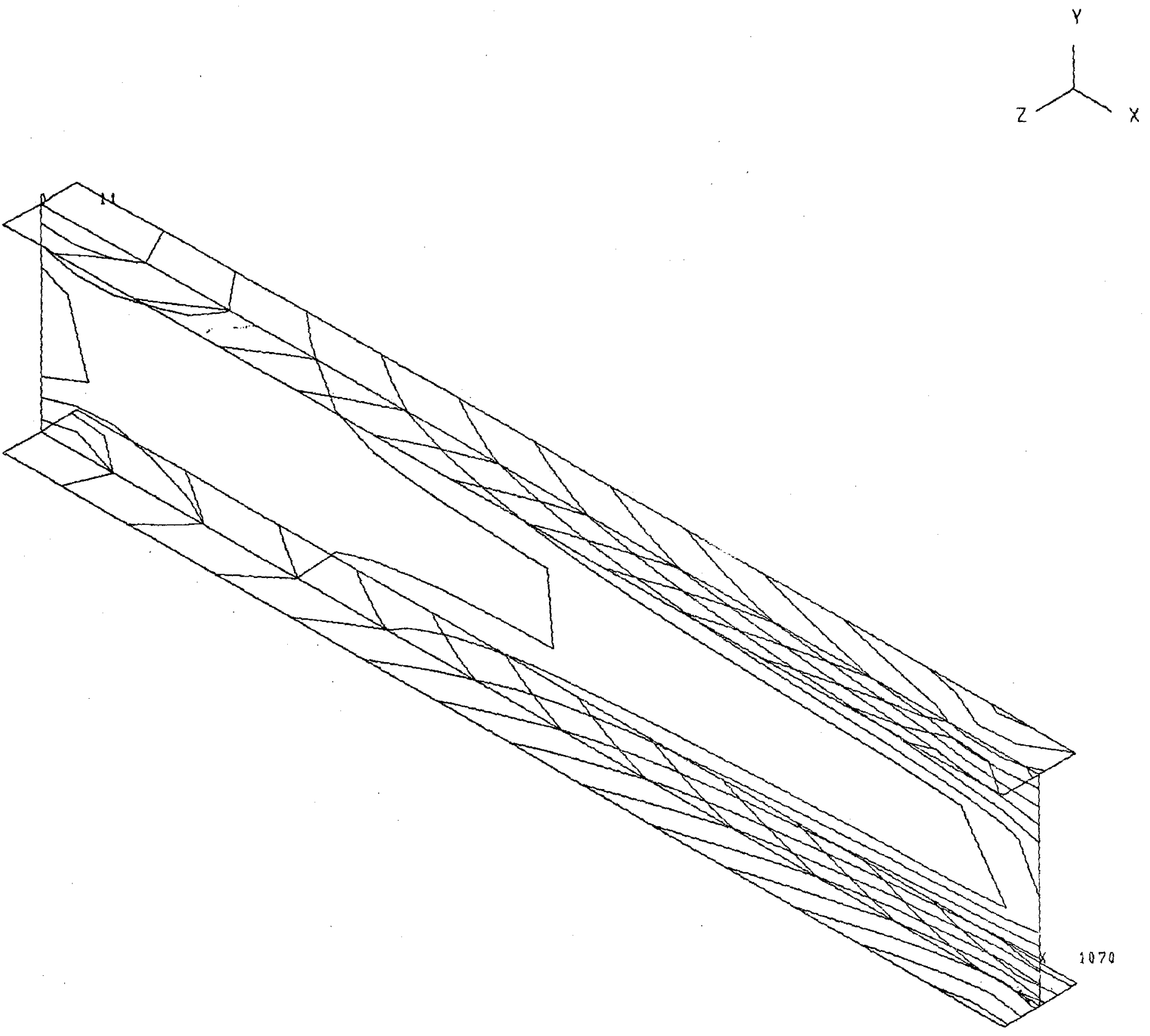
Fig. 21

STEP $=1$ ITER $=$ \& TIME $=0$
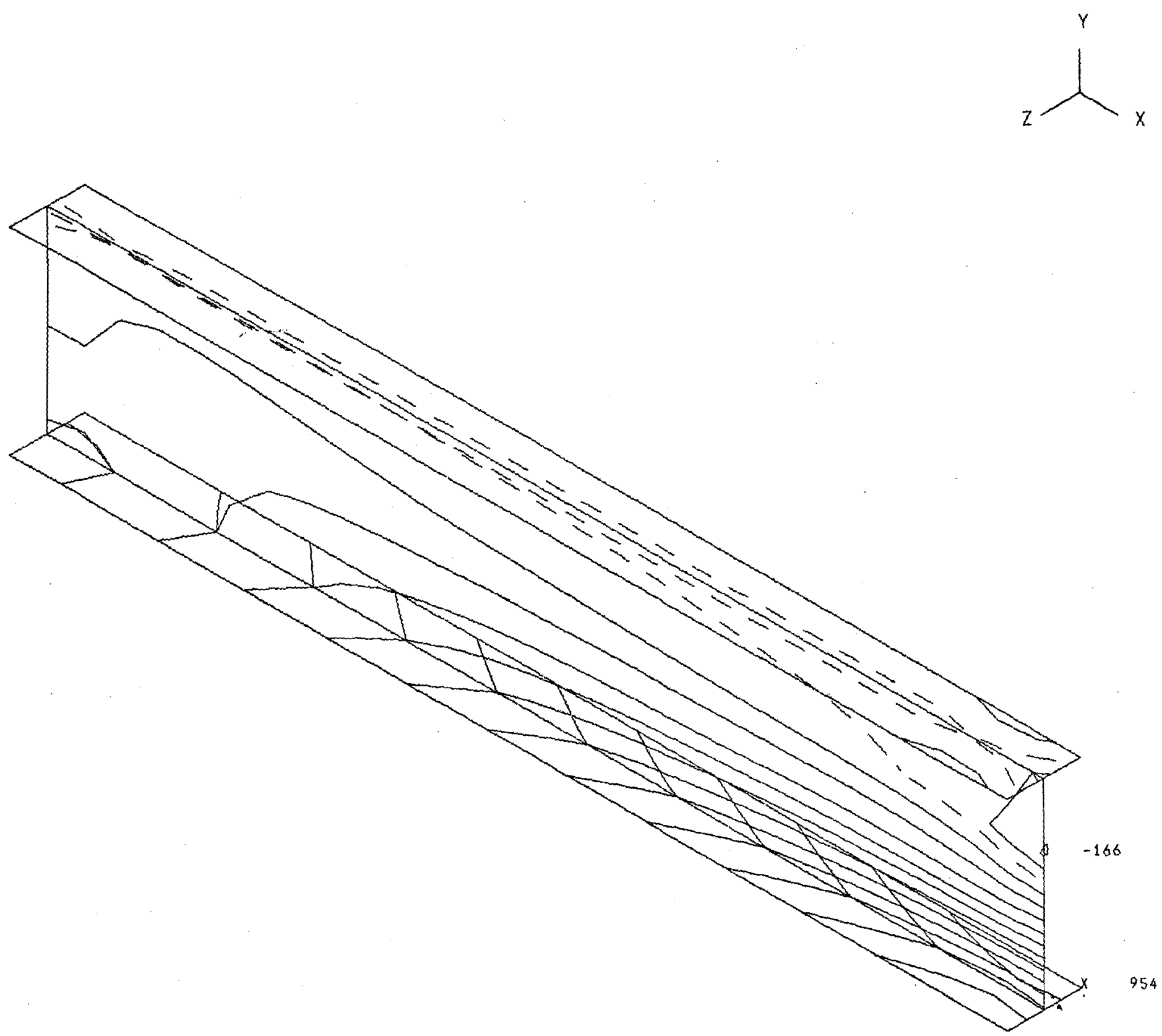
Fig. 22

STEP $=1$ ITER $=1$ TIME $=0$

80.00
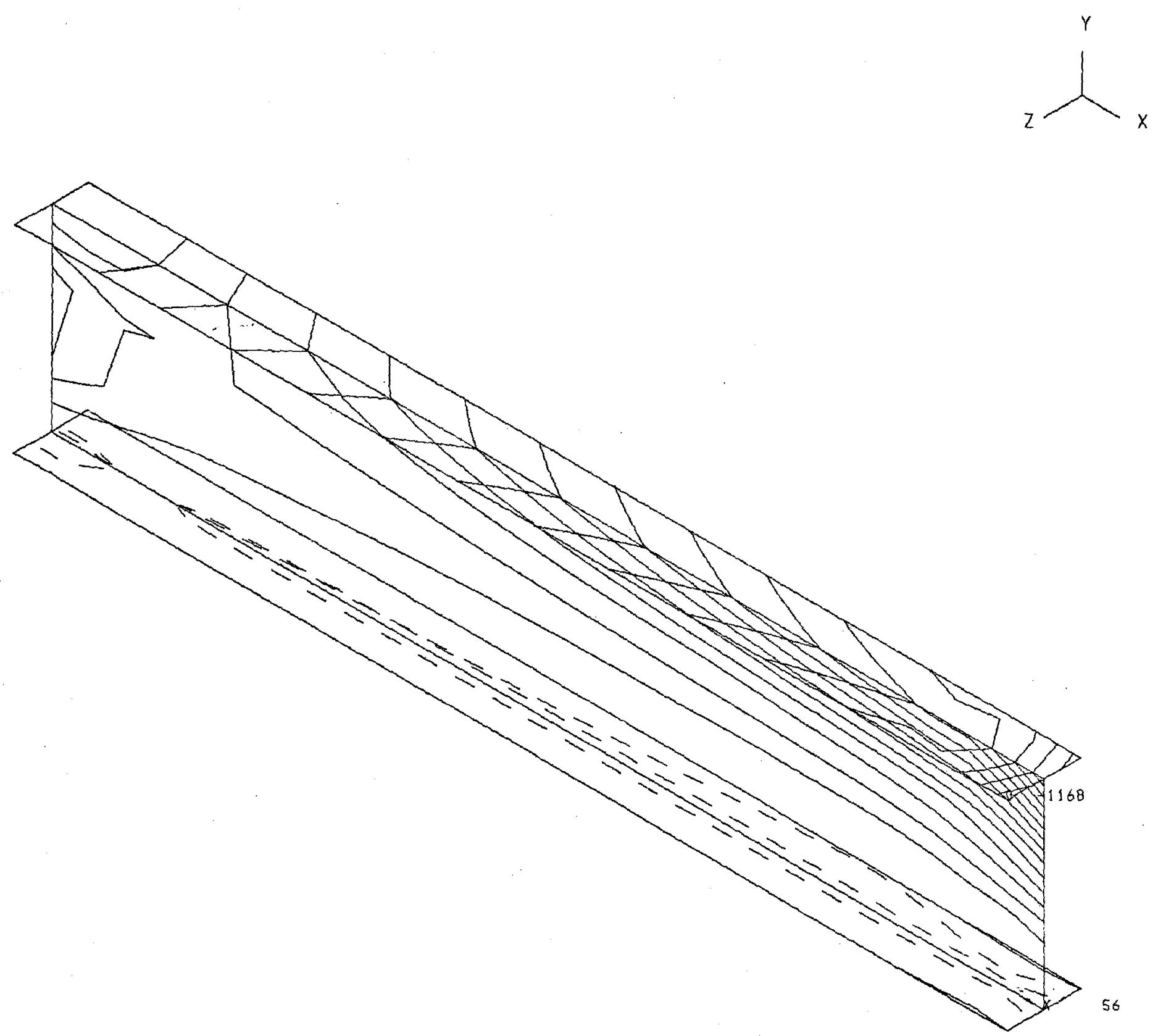
Fig. 23

STEP $=1$ ITER $=1$ TIME $=0$

40.00
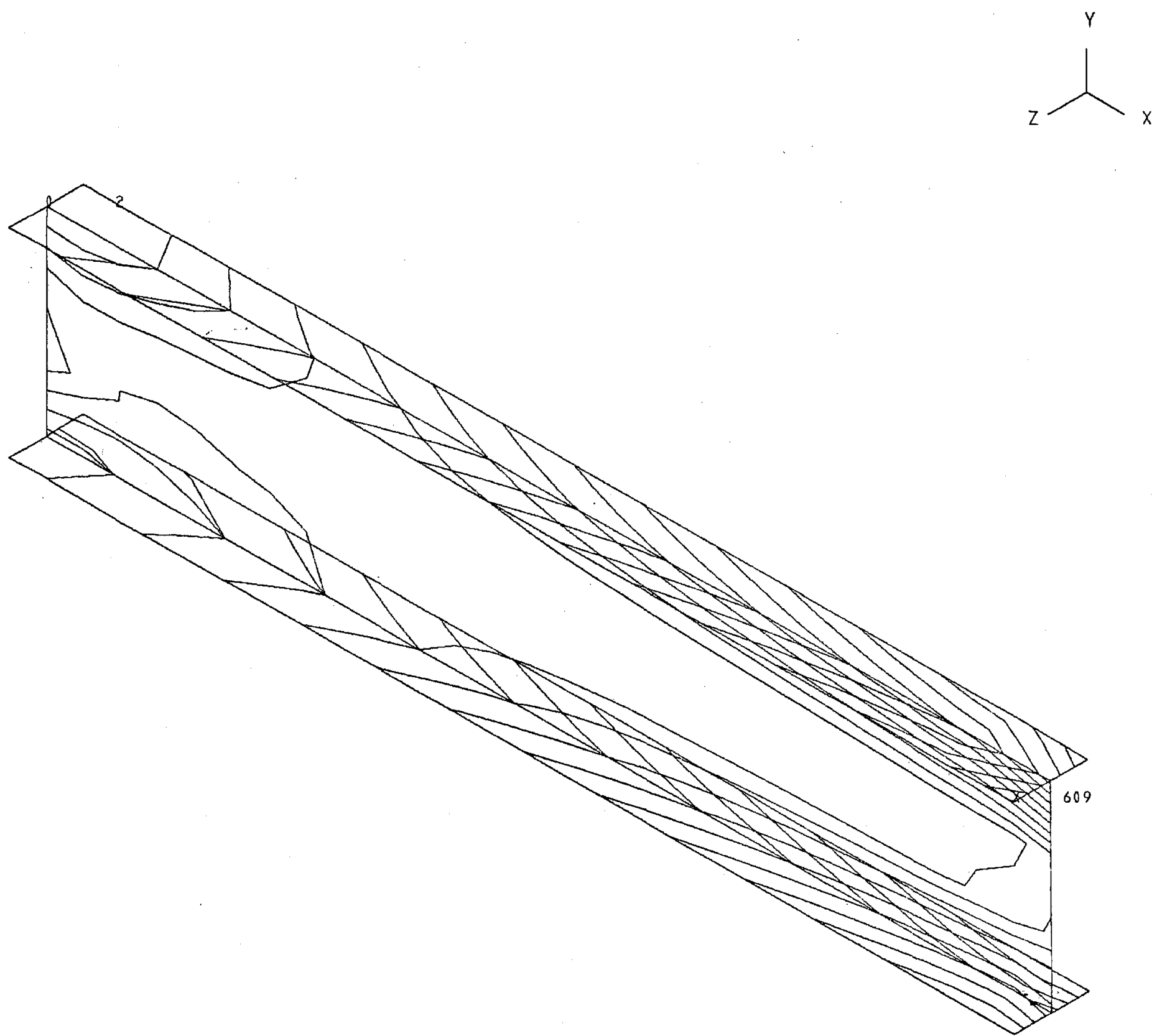
Fig. 24

STEP $=1$ ITER $=1$ TIME $=0$
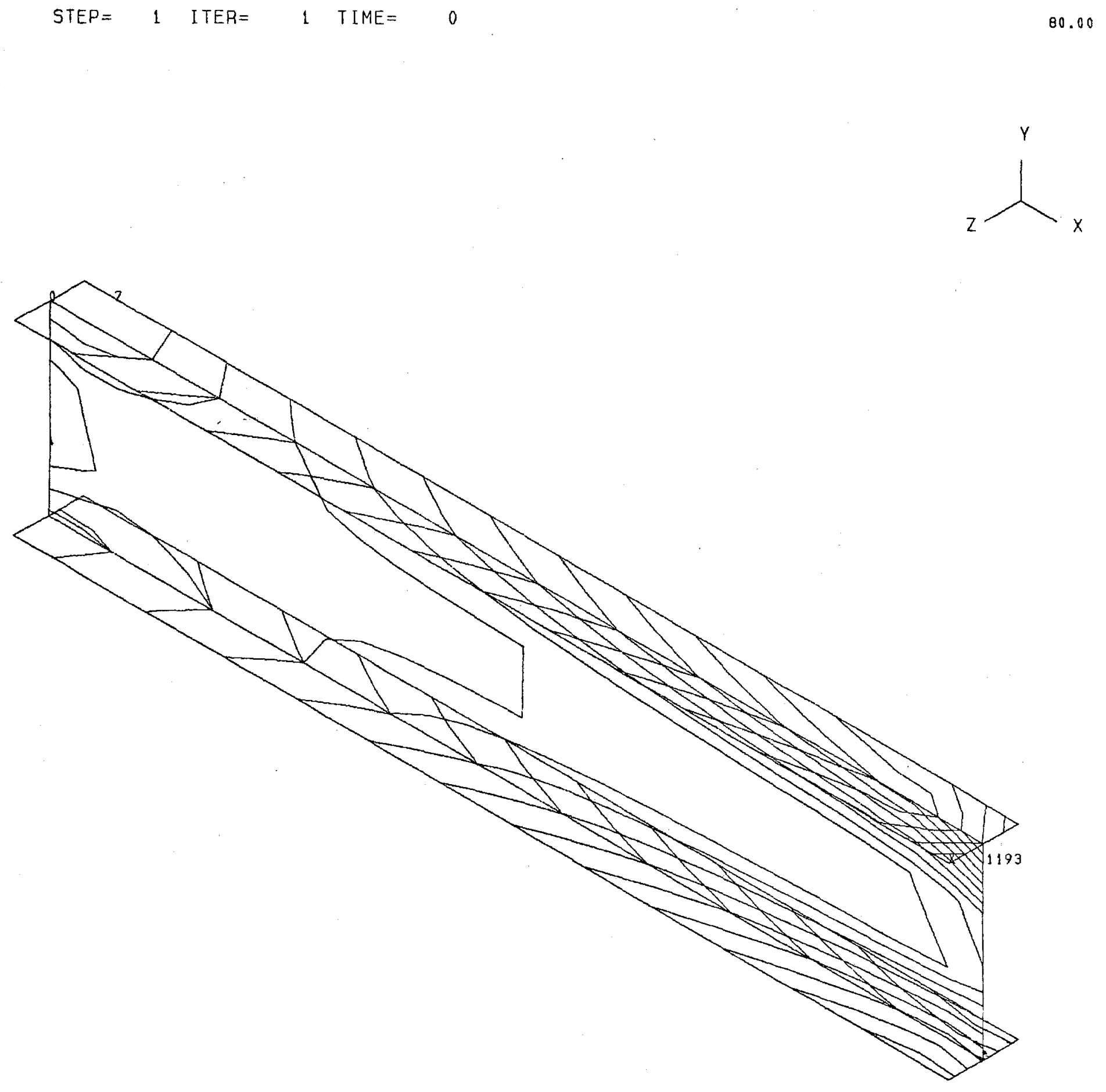
Fig. 25

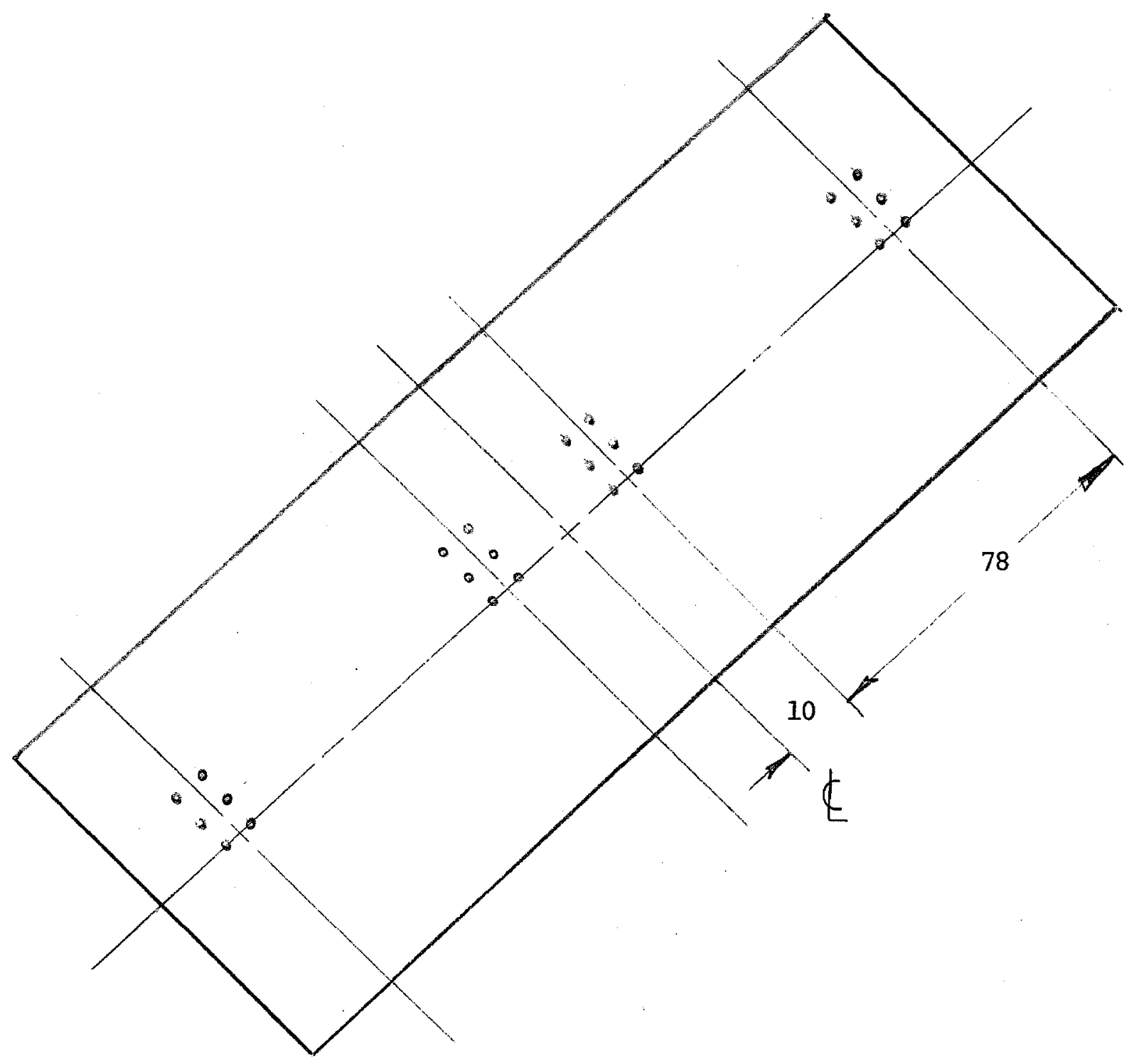

Location of loading due to Roman arch supports. Nodes are 6 in. from their nearest neighbor, each node loaded with 25,000 lbs. for a total of 75 ton per footprint. 
Fig. 26

STEP $=1$ ITER $=1$ TIME $=0$
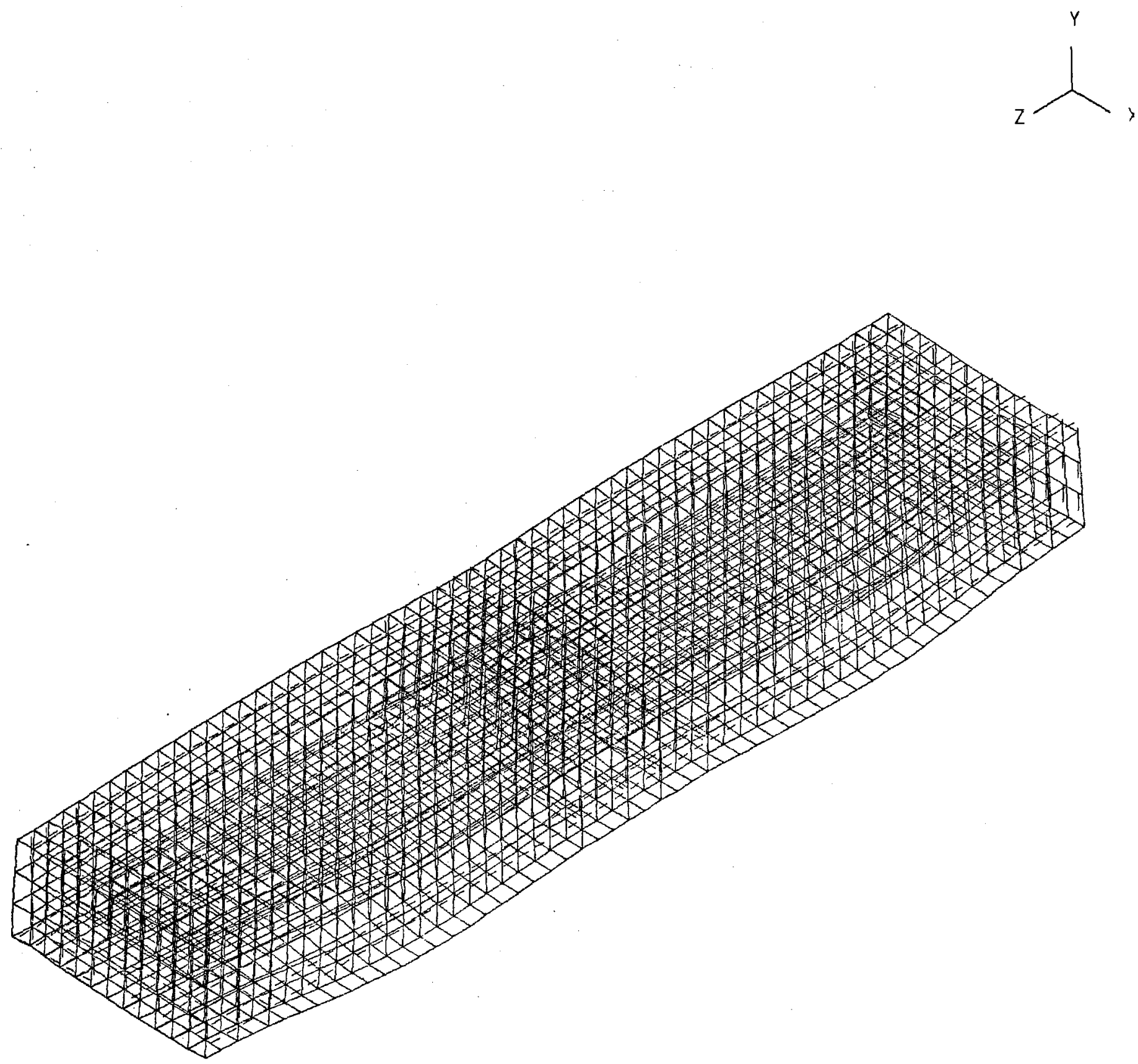
$T M-1148$

Fig. 27

STEP $=1$ ITER $=1$ TIME $=0$

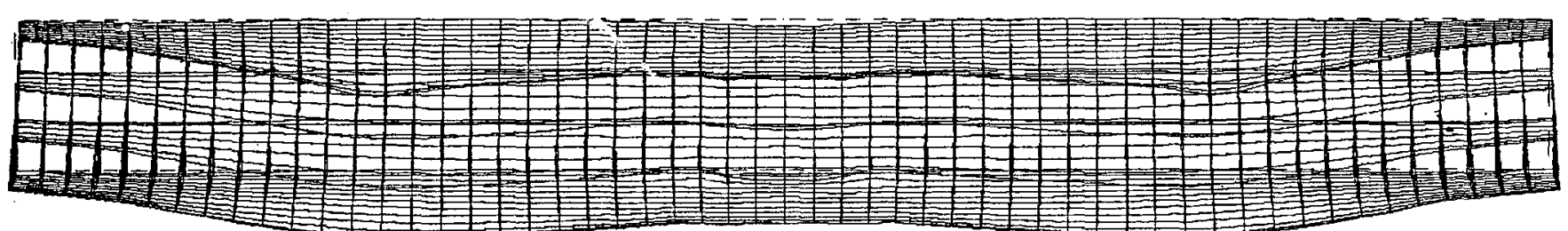


$-35-$

Fig. 28

STEP $=1$. ITER $=1$ TIME $=0$

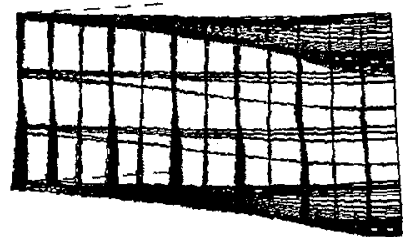


Fig. 29

STEP $=1$ ITER $=1$ TIME $=0$
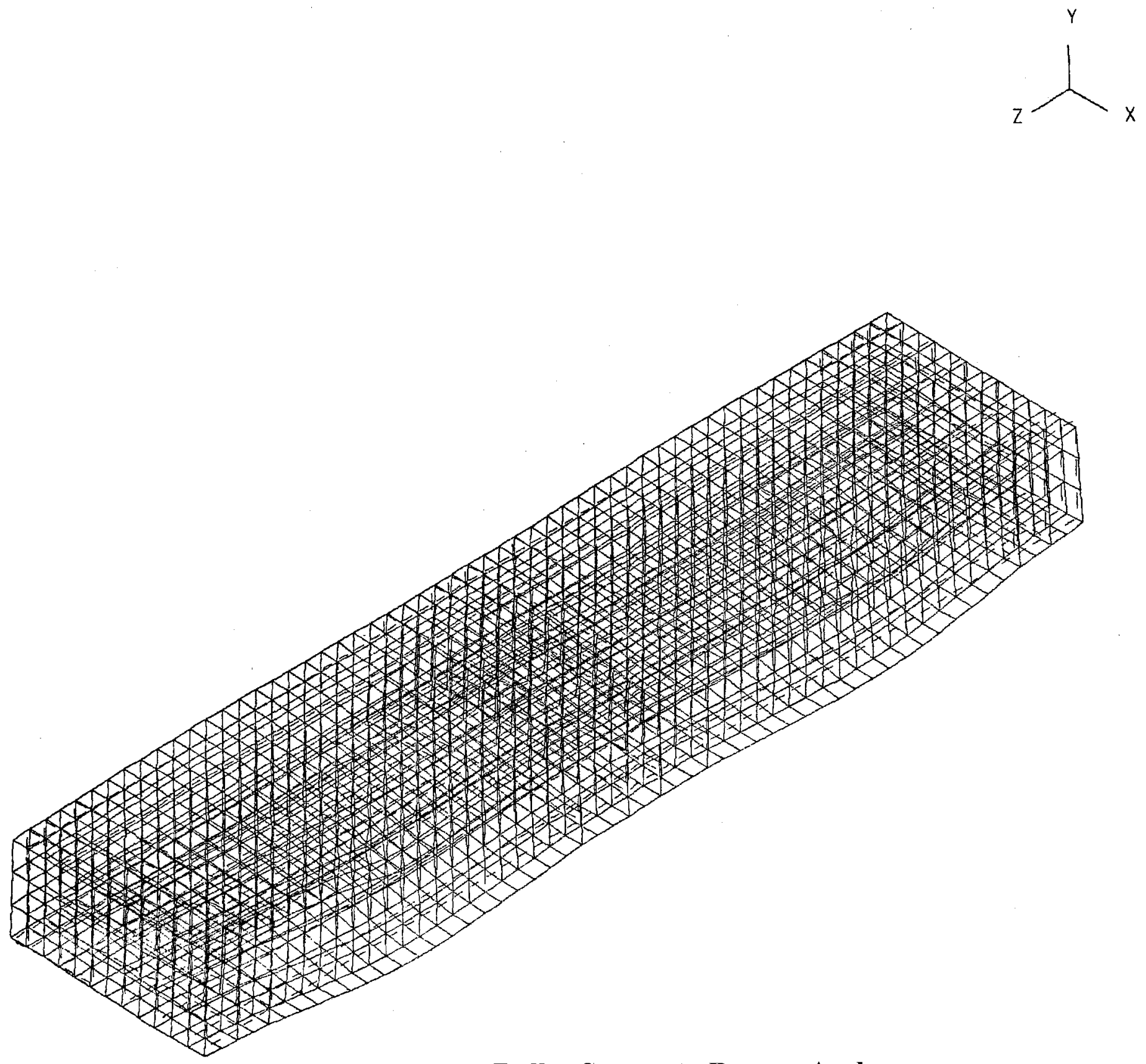

Transfer Table. Roller Support. Roman Arch 
Fig. 30

STEP $=1$ ITER $=1$ TIME $=0$

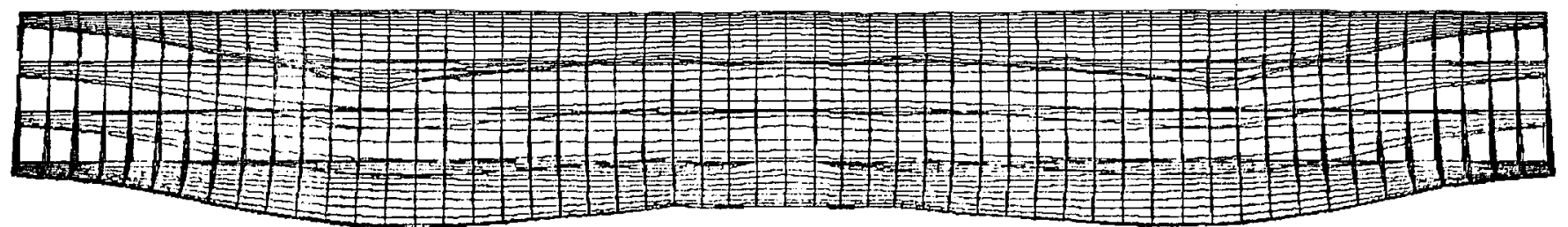


Fig. 31

STEP $=1$ ITEF $=1$ TIME $=0$

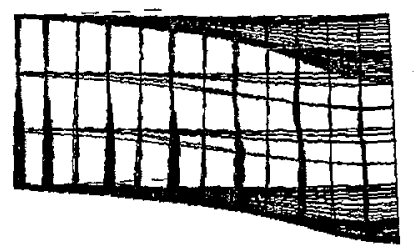

